\title{
A NOVEL TRANSCRIPTION-INTERFERENCE MECHANISM TO SUPPRESS CHECKPOINT
}

\author{
by \\ Liza Marie Hayley Calhoun \\ Bachelor of Science, Trent University, Canada, 2016
}

A thesis presented to Ryerson University

in partial fulfillment of the requirements for the degree of

Master of Science in the program of

Molecular Science

Toronto, Ontario, Canada, 2019

(C) Liza M. H. Calhoun, 2019 


\section{Author's Declaration}

I hereby declare that I am the sole author of this thesis. This is a true copy of the thesis, including any required final revisions, as accepted by my examiners.

I authorize Ryerson University to lend this thesis to other institutions or individuals for the purpose of scholarly research.

I further authorize Ryerson University to reproduce this thesis by photocopying or by other means, in total or in part, at the request of other institutions or individuals for the purpose of scholarly research.

I understand that my thesis may be made electronically available to the public. 


\begin{abstract}
A NOVEL TRANSCRIPTION-INTERFERENCE MECHANISM TO SUPPRESS CHECKPOINT
\end{abstract}

Liza Marie Hayley Calhoun, Master of Science in Molecular Science, Ryerson University, 2019

Meiosis is a linear differentiation pathway remarkable for deliberate DNA damage. During meiotic prophase, DNA damage checkpoint is repressed, which may promote homologous recombination and repair. Meiotic breaks are known to influence meiotic chromosome segregation, preventing aneuploidy in gametes. Convergent genes cause transcriptional interference through overlapping transcripts, resulting in gene suppression. This general mechanism of gene silencing has been noted in both yeast and metazoans. In Schizosaccharomyces pombe, $c h k{ }^{+}$is convergent with the meiotically upregulated $m e u 27^{+}$gene. Through gain- and loss-of-function assays we are developing a model of checkpoint regulation during nitrogen stress. We find that altered $m e u 27^{+}$ expression impacts $c h k 1^{+}$mRNA levels, DNA segregation, and cell cycle progression. S. pombe encodes several DNA damage checkpoint genes that are convergent with stress-inducible transcripts. Therefore, we investigate the possibility that convergent transcription is a mechanism altering DNA damage repair during other stresses and differentiation programmes which may trigger unregulated cell division. 


\title{
Acknowledgements
}

\author{
It takes a village.
}

First and foremost, I would like to express my sincere appreciation for all the encouragement and support from my supervisor, Dr. Sarah Sabatinos, throughout my time in her lab. Not only did she guide and direct my research, but she went above and beyond to help in every aspect of my career development. With her on my side it was possible to pursue the path less travelled toward my professional goals.

My committee members, Dr. Costin Antonescu and Dr. Joseph McPhee, provided valuable insight to broaden the scope of my knowledge surrounding my research, and for this I am truly grateful. Also, Dr. Warren Wakarchuk, my former mentor, has always been a source of inspiration and the one whom I owe tremendous gratitude for sparking my interest in the molecular sciences. This established a solid foundation during my early years that has allowed my passion to flourish.

Many thanks to the Sabatinos Lab for all their support, particularly Kyle Cheung, who helped with various experiments even when time was not on our side. And a special thank you goes out to Zohreh Kianfard, my colleague and dear friend, who I can turn to in the happy and not-so-happy times we all face in research.

I would also like to thank Sarah Kovacs and Stephanie Grouios for their abundant supply of information any time I had questions or concerns about the next steps. Lastly, I am grateful for Ryerson University, NSERC Discovery Grant program, and NSERC CGS-M for funding my work and making this opportunity a reality.

From the bottom of my heart, thank you all for the time you took to help me in my personal and professional development to become the scientist I am today. 


\section{Contents}

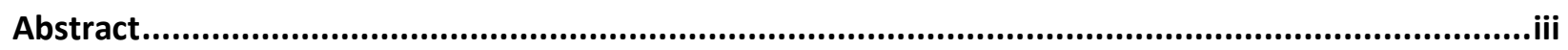

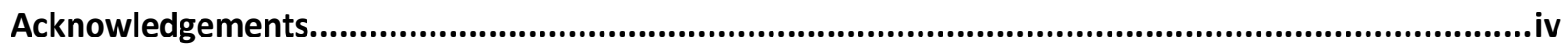

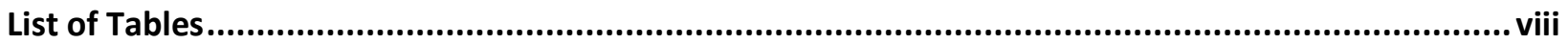

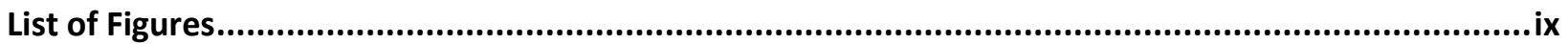

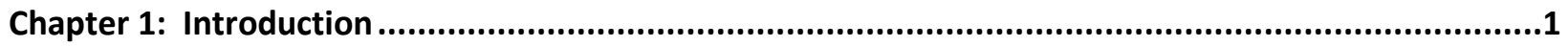

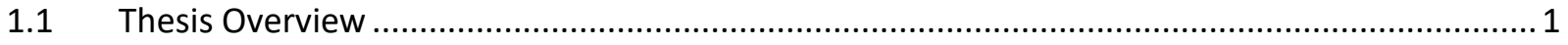

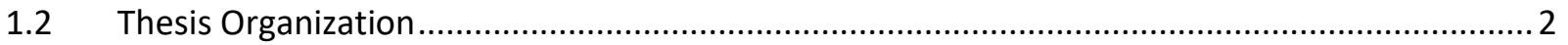

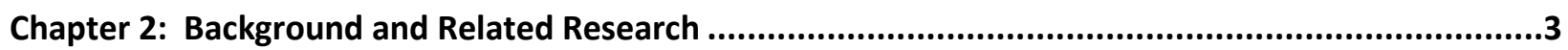

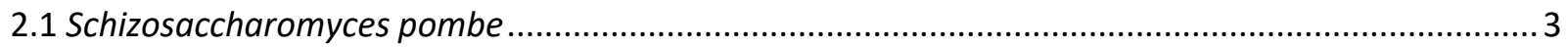

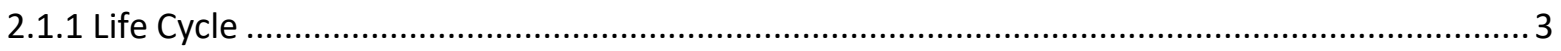

2.1.2 Model Organism............................................................................................................ 4

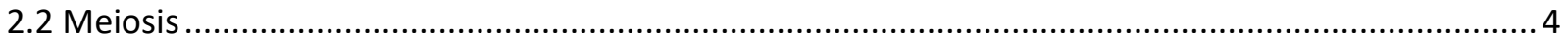

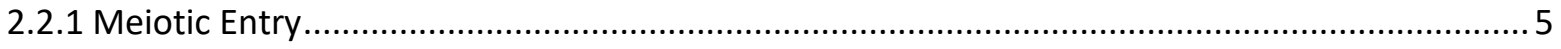

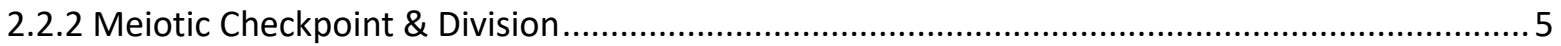

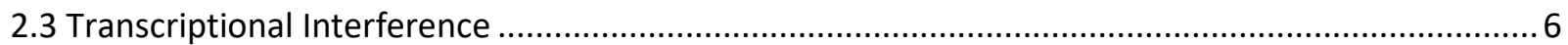

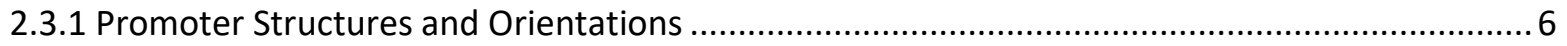

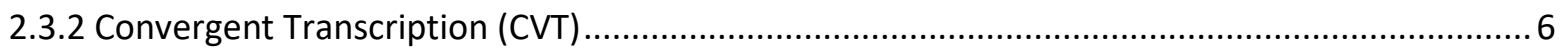

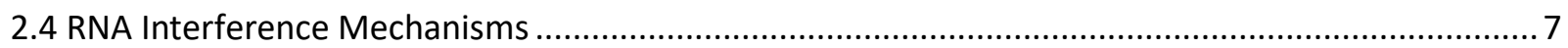

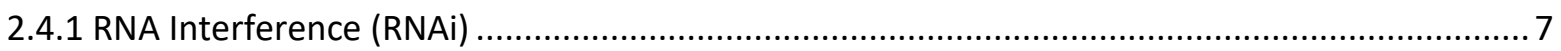

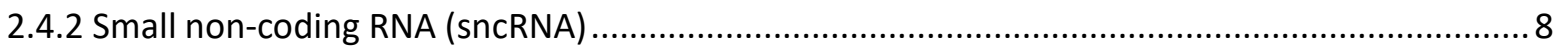

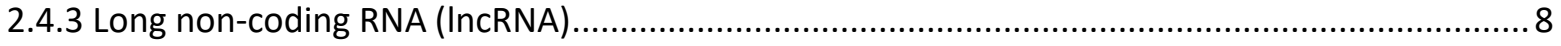

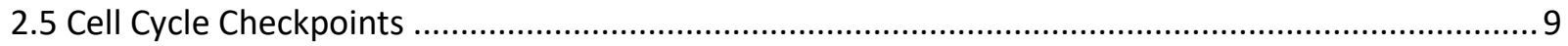

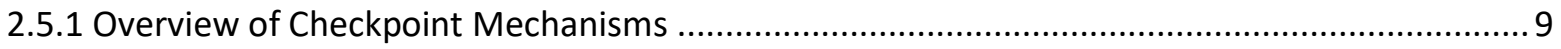

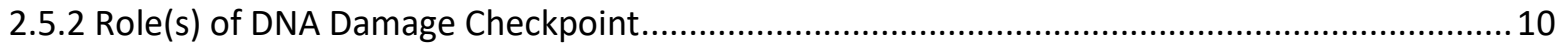

2.5.3 Convergent Gene Pairs and Checkpoint Proteins .................................................................11

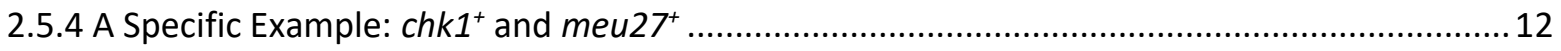

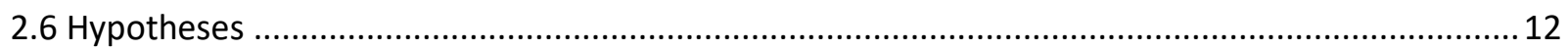

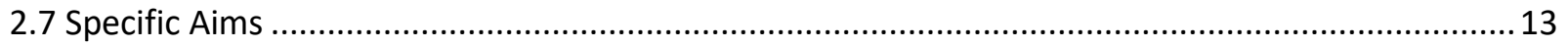




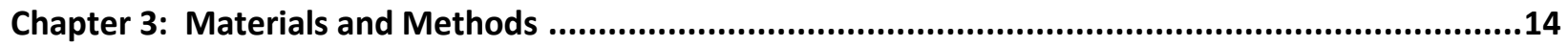

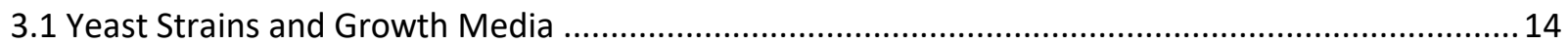

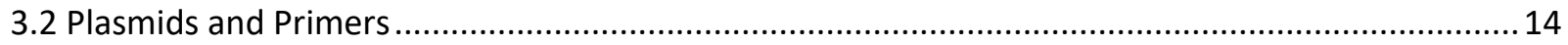

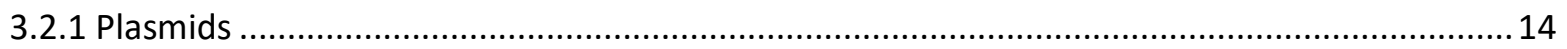

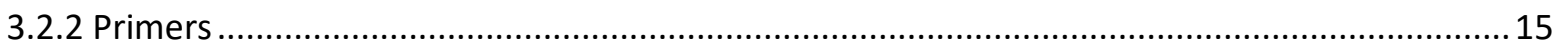

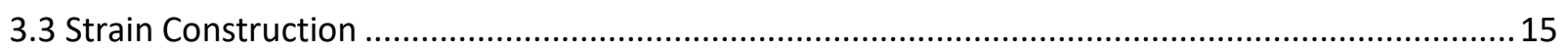

3.3.1 Polymerase Chain Reaction (PCR)-Based Gene Targeting .................................................. 15

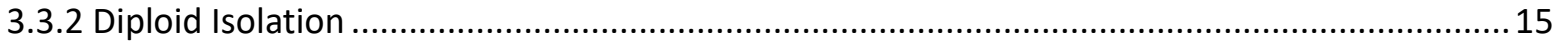

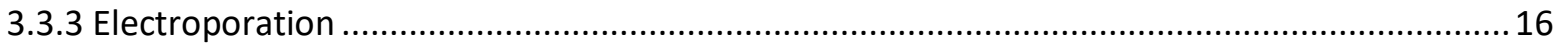

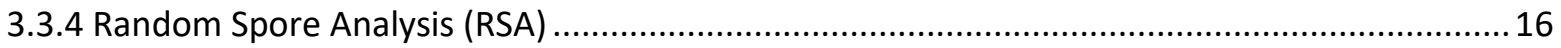

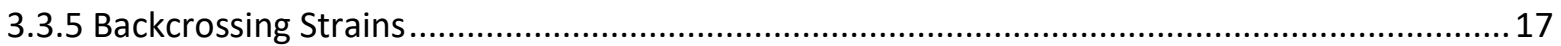

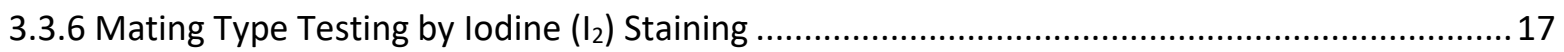

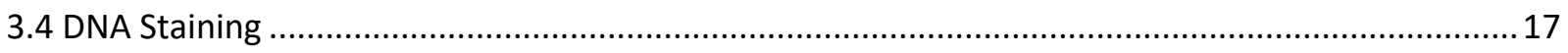

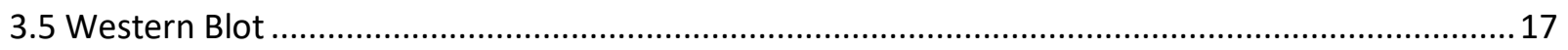

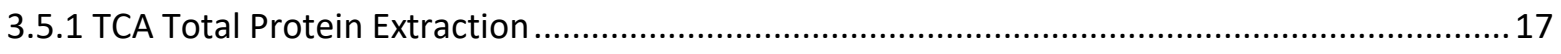

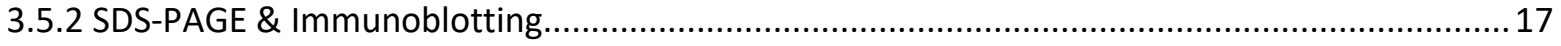

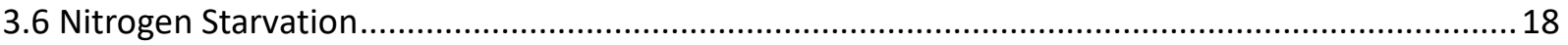

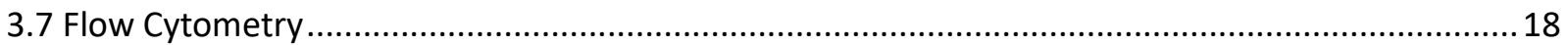

3.8 Quantitative Reverse Transcription PCR (RT-qPCR) ............................................................... 18

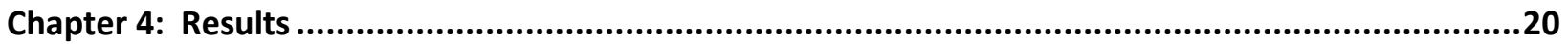

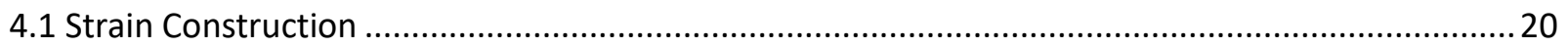

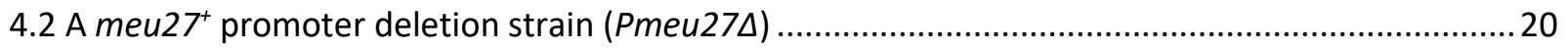

4.2.1 Pmeu27 4 phenocopies $c h k 1^{+}$overexpression during meiosis................................................20

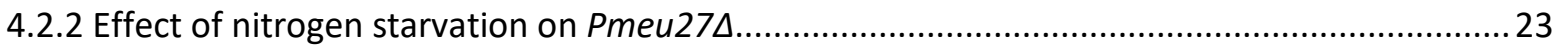

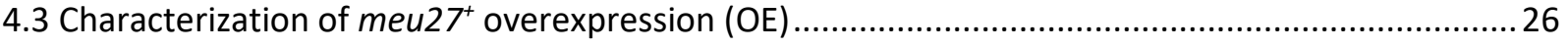

4.4 Effect of a chk1 $1^{+}>$KanMX6>><<meu27 $7^{+}$broken transcriptional unit .........................................28

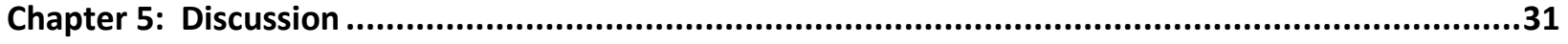

5.1 Evidence for convergent transcriptional effects on chk1 $1^{+}$expression............................................ 31

5.2 Potential for checkpoint regulation by convergent transcription .................................................33

5.3 The impact of environmental stress on checkpoint regulation ....................................................35 


\section{CONTENTS}

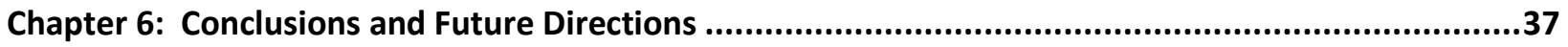

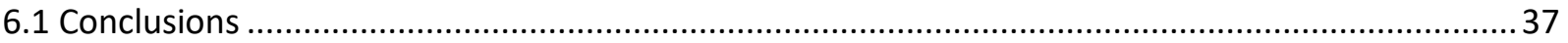

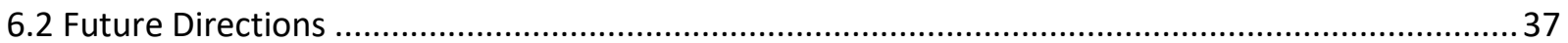

Appendix A: DNA Damage Checkpoint Convergent Pairs ….......................................................39

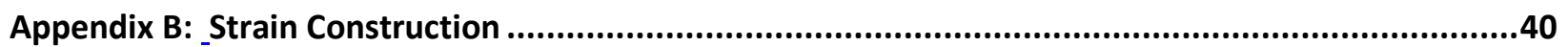

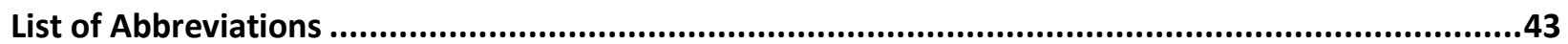

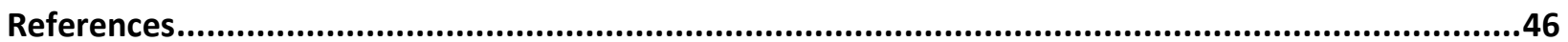




\section{List of Tables}

Table 2.1 Conserved checkpoint protein homologues .............................................................................

Table 3.1 Yeast strains used in this research project ...................................................................................14

Table 3.2 Primers used for strain construction ......................................................................................15

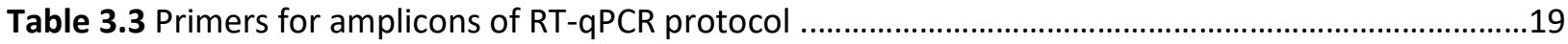




\section{List of Figures}

Figure 2.1 The Life Cycle of Schizosaccharomyces pombe …..............................................................

Figure 2.2 DNA damage and DNA replication checkpoint kinase cascades .......................................... 10

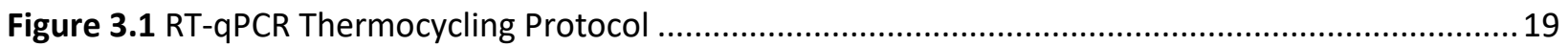

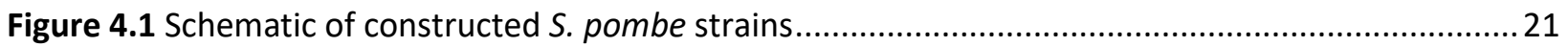

Figure 4.2 Quantification of meiotic events to evaluate Pmeu27D progression through meiosis.............22

Figure 4.3 Chromosome mis-segregation in Pmeu27 following meiosis and sporulation ......................23

Figure 4.4 Frequency of abnormal meiotic events in Pmeu27 $\Delta$ crosses .............................................24

Figure 4.5 Effect of nitrogen starvation on Pmeu27 4 on cell cycle kinetics ...........................................25

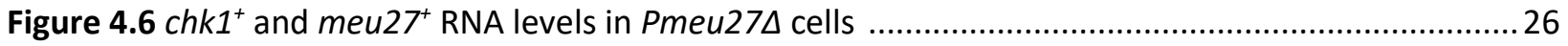

Figure 4.7 Effect of nitrogen starvation on meu27 $\mathrm{OE}$ cell cycle kinetics .............................................27

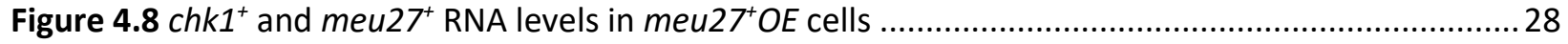

Figure 4.9 Effect of nitrogen starvation on $c h k 1^{+} /$meu $27^{+}$cell cycle kinetics ........................................29

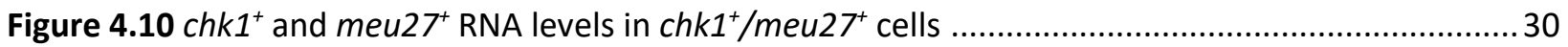

Figure A1 Chromosome mapping of convergent DNA damage checkpoint genes ................................39

Figure B1 Confirmation of Pmeu27 strain construction ….......................................................... 40

Figure B2 Confirmation of meu2 $7^{+} \mathrm{OE}$ strain construction .............................................................. 41

Figure B3 Confirmation of $c h k 1^{+}>>K a n M X 6>><<m e u 27^{+}$strain construction ........................................42

Figure B4 Comparison of wild-type and Chk1-HA RNA levels .......................................................... 42 


\section{Chapter 1:}

\section{Introduction}

\subsection{Thesis Overview}

Cell cycle checkpoints ensure that cellular division occurs only under favourable conditions and that genetic stability and integrity are maintained throughout this process. The DNA damage checkpoint prevents the transition between the second gap phase, $G 2$, and mitosis, $M$ phase, in the presence of double stranded breaks (DSBs) in DNA. DNA DSBs are capable of killing a cell if transmitted to subsequent generations and are considered one of the most lethal forms of DNA damage. Regulation of the DNA damage checkpoint is essential to arrest the cell cycle when DNA is damaged, and then allow cellular division once any damage has been repaired. Many genes involved in DNA damage checkpoint are convergent with potential stress-inducible genes, suggesting a novel regulatory mechanism of checkpoint at the level of transcription. Convergent transcription suppresses gene expression, which may prevent checkpoint activation. The gene encoding the DNA damage checkpoint effector kinase, chk $1^{+}$, is convergent with $m e u 27^{+}$, a gene that produces a meiotically upregulated protein. Meiosis is a differentiation process that involves deliberate DNA damage in the form of DSBs during homologous recombination. When damage is induced during meiosis, DNA damage checkpoint is not activated. We investigate the effect of convergent transcription on checkpoint suppression and aim to determine whether environmental stress can alter checkpoint through this transcriptional-interference mechanism. We used fission yeast, Schizosaccharomyces pombe (S. pombe), to study the effect of convergent transcription on $c h k 1^{+}$levels and checkpoint activation during nitrogen starvation and recovery. We demonstrate that convergent transcription of meu2 $27^{+}$directly impacts $c h k 1^{+}$expression and disrupting the convergent orientation of these genes results in unregulated expression. In addition, we show that the transcriptional interference has the potential to impact checkpoint regulation under varying environmental conditions. The data obtained from this study improves our understanding of how transcription modulates checkpoint under normal and adverse conditions. A more thorough knowledge of mechanisms maintaining checkpoint regulation ultimately provides insight as to how cancer cells evade checkpoint and proliferate uncontrollably. 
1 INTRODUCTION

\subsection{Thesis Organization}

There are six chapters in this thesis. Chapter 2 highlights the key concepts and related research that lead to the rationale behind the hypotheses of this study and lists the specific aims of the project. Chapter 3 describes in detail the methods used to conduct the experiments involved in testing the hypotheses. Chapters 4 states the major findings of the research and Chapter 5 discusses these results in more depth. Chapter 6 concludes the study with a brief summary of the thesis project and suggests future work to further the research in this particular field. 


\section{Chapter 2:}

\section{Background and Related Research}

This chapter is an introduction to the DNA damage checkpoint during mitotic division and meiotic differentiation in fission yeast. In addition, I review transcriptional interference mechanisms since they are related to our investigation of the role of convergent transcription on checkpoint suppression.

\subsection{Schizosaccharomyces pombe}

The ancient yeast species Schizosaccharomyces pombe (S. pombe), known as fission yeast, is a unicellular ascomycete fungus, a distant cousin of Saccharomyces cerevisiae (S. cerevisiae), or budding yeast. Unlike S. cerevisiae, S. pombe divides using medial fission and therefore grows in length, not width, producing its natural rod shape of approximately $7-14 \mu \mathrm{m}$ long and $4 \mu \mathrm{m}$ wide [1].

\subsubsection{Life Cycle}

Fission yeast generally exist in a haploid state during mitotic divisions. A transient diploid stage is passed during sexual differentiation. Vegetative, or mitotic growth, can be divided into four distinct phases: G1 (gap 1), S phase (DNA synthesis), G2 (gap 2), and M phase (mitosis). During meiosis, two haploid cells conjugate to form a diploid zygote. The nuclei of the two cells fuse, chromosomes pair, and DNA is replicated. Following DNA replication, the zygote pair undergoes two rounds of meiotic division (meiosis I and meiosis II) to produce four spores within a tetrad ascus (refer to Fig 2.1).

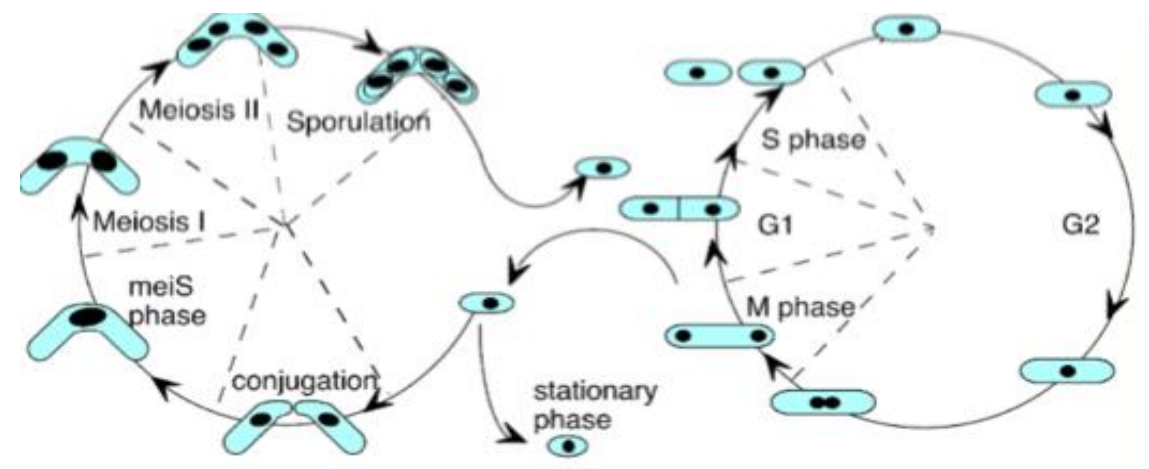

Meiotic cells

Vegetative cells

Figure 2.1 The Life Cycle of Schizosaccharomyces pombe

The four phases of the vegetative mitotic cycle of haploid cells is shown on the right: $\mathrm{G} 1(10 \%)$, S phase (10\%), G2 (70\%), and M phase (10\%); percentages indicate approximate portion of time a cell spends in each phase. Under select internal or external factors cells may conjugate to enter a transient diploid state, followed by two meiotic divisions (shown on the left). At this stage there is an exchange of genetic information followed by sporulation to produce four unique daughter cells. Figure adapted from [2]. 


\section{BACKGROUND AND RELATED RESEARCH}

\subsubsection{Model Organism}

Both S. cerevisiae and S. pombe are popular model organisms for studying eukaryotic molecular and cellular biology. Not only are they inexpensive and easy to grow, but they are genetically tractable, and ideal for laboratory experiments into basic molecular mechanisms. The two species diverged approximately 350 million years ago [1]. S. pombe is believed to have evolved at a slower rate allowing it to retain more features of the common yeast ancestor [1]. This is believed to explain the higher conservation of proteins and pathways between fission yeast and vertebrates (metazoans in general), which are absent in budding yeast. An important example of evolutionary changes in S. cerevisiae that exemplify this distance from higher eukaryotic cells is the absence of RNA interference (RNAi) machinery. The loss of RNAi in S. cerevisiae has been proposed to be linked to the loss of most intronic DNA and complex centromeric regions. Of note, both intron structures and repetitive centromeres are conserved in S. pombe [1], making fission yeast the model of choice for studies on transcriptional regulation and chromosome stability. In some cases, RNAi proteins have a role in transcriptional interference mechanisms, therefore, fission yeast are a more appropriate model organism for our project.

The nuclear $S$. pombe genome is approximately $13.8 \mathrm{Mb}$, which is divided into three chromosomes: chromosome I (5.7Mb), chromosome II (4.6Mb), and chromosome III (3.5Mb). The fission yeast cell cycle is 2-4 hours from G1 to daughter cell. These factors facilitate studies of cell cycle and genomics investigation compared to mammalian cell lines. Many fission yeast genes have been well characterized, including those involved in DNA damage checkpoint, and homologues of their mammalian checkpoint counterparts have been identified [3]. In addition, deletion and overexpression of target genes in haploid yeast cells is easier to evaluate than in diploid mammalian cells where a recessive trait may not be evident. For these reasons, $S$. pombe is an ideal model organism in which to study convergent transcriptional effects on cell cycle checkpoints.

\subsection{Meiosis}

Meiosis is a linear differentiation pathway that deliberately induces DNA damage in order to allow for events such as homologous recombination and repair. Once meiotic entry is triggered by conjugation and diploidy, wide-spread transcriptional changes occur leading to two rounds of division that produce four haploid gametes. Strict regulation of this division process is required to ensure correct genetic recombination and chromosome segregation to produce viable offspring. 


\subsubsection{Meiotic Entry}

In eukaryotes, sexual differentiation is controlled by individual promoters that act as master regulators or 'switches' that initiate changes within the transcriptome, committing cells to meiotic division. The master regulator of meiotic entry in budding yeast is the IME1 (initiator of meiosis I) promoter, and in fission yeast it is the $s t e 11^{+}$(Sterile 11) promoter [4]. Many intrinsic and extrinsic cellular signals converge at these promoters to coordinate expression. In S. pombe, the most critical environmental cue that initiates entry into gametogenesis is a nutritional signal that is produced under nitrogen starvation. When the nitrogen source has been depleted, cells enter an uncommitted G1 phase for a short period of time before committing to meiotic differentiation, if mating type heterozygosity signals are present [5]. Together, these signals control ste $11^{+}$expression which in turn activates transcription of genes involved in mating and early stages of sporulation [4]. Other pathways affect mating and sporulation through ste $11^{+}$regulation in response to the nutritional environment, including the protein kinase A (PKA) and target of rapamycin (TOR) signalling transduction pathways [4], [6]. This demonstrates that environmental stressors indirectly influence transcriptional changes within a cell which may be used to modulate downstream networks.

Genome-wide studies have shown that transcript levels fluctuate extensively during nitrogen starvation and meiotic development. However, the molecular mechanisms driving these changes remain largely unknown [7]. We do know that regulation of meiotic gene expression can occur at transcriptional, post-transcriptional, and translational levels, as well as through exon-skipping and alternative splicing events [8], [9]. One facet of modulating gene expression is through non-coding RNAs (ncRNAs), the major component of RNA interference (RNAi) mechanisms. ncRNA have known roles in differentiation, selfrenewal, and apoptosis, with implications in controlling commitment and execution of cell-fate programs during development [10]-[12]. Each of these pathways requires dramatic changes to the transcriptome, many of which are precisely orchestrated through various mechanisms involving different ncRNAs, as described in section $\mathbf{2 . 4}$.

\subsubsection{Meiotic Checkpoint \& Division}

After meiotic entry, cells undergo DNA synthesis in meiotic S-phase (meiS) which is followed by a programmed homologous recombination step in prophase. A meiotic checkpoint operates during each of these phases to ensure the completion of DNA synthesis and successful recombination before division, respectively [13]. However, these checkpoints differ from typical checkpoints activated in the mitotic cell cycle due to the unique need of deliberately generating double-stranded breaks (DSBs) during 
recombination. In fission yeast, the meiotic checkpoint is exceptionally tolerant of DNA damage compared to mitotic checkpoints, and the effector kinase of the DNA damage checkpoint, Chk1, is not activated (phosphorylated) [13]. Permissive DSBs combined with the absence of an increase in checkpoint activation allows for a 'bypass' of cell cycle arrest in the presence of DNA damage. Molecular mechanisms governing this checkpoint evasion are not well understood, nor is their implication in response to other environmental stresses that may modulate the DNA damage threshold and prevent checkpoint activation.

\subsection{Transcriptional Interference}

Transcriptional interference is a wide-spread mechanism of gene regulation in a range of organisms and biological functions. Transcriptional interference encompasses multiple mechanisms that interfere with the process or the product of transcription. Typically, this involves one transcriptional process having a negative or suppressive effect on another transcriptional process, directly and in cis [14]. The numerous regulatory roles for transcriptional interference are just starting to be characterized. Transcription interference has been identified as the primary maintenance mechanism of latent HIV infections, and atypical regulation has been shown to result in human genetic disorders [15], [16]. The research in this thesis aims to contribute to a more thorough understanding of transcriptional interference mechanisms and their impact on the many biological processes, which have become of growing importance in this particular field.

\subsubsection{Promoter Structures and Orientations}

Approximately $40 \%$ of human transcripts having overlapping transcripts [15], therefore, the orientation and placement of promoters becomes an important factor influencing transcriptional interference. Overlapping transcripts may act as switches and/or feedback mechanisms as well as alternate transcriptional start sites (TSSs), depending on the promoter [14]. Promoters situated on the same DNA strand are in a tandem orientation. Promoters that are on opposite DNA strands may be oriented in either a divergent (directed away from each other) or convergent (directed towards each other) manner. All of these promoter locations use a variety of transcriptional interference mechanisms to suppress transcription of the paired gene [15], [17].

\subsubsection{Convergent Transcription (CVT)}

Detailed mechanisms of convergent transcription (CVT) interference are still poorly understood. Some recent studies have confirmed that general mechanisms involved can be either direct and in cis or indirect and in trans. During transcription, DNA-dependent RNA polymerases (RNAPs) may encounter 
obstacles including DNA-bound transcription factors (TFs), structural DNA-binding proteins, or other RNAPs which can impact one or both of the transcriptional processes [15]. In cis transcriptional interference by physical collision of RNAPs results when convergent promoters are situated close together, or when one of the two convergent promoters is considerably stronger than its counterpart, despite the inter-promoter distance [15]. This direct form of CVT has been observed in organisms from viruses (coliphages 186 and $\lambda$ ) to eukaryotes such as yeast where it serves as the regulatory mechanism governing meiotic entry in S. cerevisiae [15], [18]. Such evidence linking CVT with meiotic regulation further suggests that environmental factors modulate transcription.

In trans, CVT of sense and anti-sense RNA gene pairs has been shown to downregulate or suppress expression in an RNA interference (RNAi)-like manner [19], [20]. Co-expression of identical convergent promoters flanking a target gene was used in studies with trypanosomes, Drosophila, and even S. pombe, that produced longer lasting effects than RNAi alone [19], [21]-[23]. Regulatory mechanisms responsible for this effect are yet to be characterized, although it is possible that some of the same RNAi machinery may be involved. In addition, it is unclear whether this similar mechanism is at play when the CVT pair consists of two protein-coding genes.

\subsection{RNA Interference Mechanisms}

RNA-mediated repression or RNA interference mechanisms are post-transcriptional biological processes that use non-coding RNA (ncRNA) molecules to suppress gene expression. It is known that only a small portion ( $2 \%$ ) of the human genome is translated to protein, yet $70-90 \%$ is transcribed to RNA [24], [25]. Also, ncRNA transcripts are regulated independently of coding RNA transcripts [26], implying that ncRNAs comprise an entire covert network to regulate gene expression. As a potential component of the transcriptional interference mechanism proposed in this research, a basic understanding of RNAi and the two classes of ncRNA, small and long ncRNA, are outlined in this section.

\subsubsection{RNA Interference (RNAi)}

RNA interference (RNAi) is a well-known mechanism that uses small interfering RNA (siRNA) molecules as templates to bind target RNA and form double-stranded RNA (dsRNA), which is then cleaved with help from the RNA-induced silencing complex (RISC) and eventually degraded [19], [27]. Many of the genes that encode RNAi machinery such as the Dcr1 DICER ribonuclease, Rdp1 RNA-dependent RNA polymerase, and Ago1 Argonaute family member have all been conserved in S. pombe [1]. Research on RNAi in this simpler, single-celled organism has contributed to our understanding of the mechanisms and 
outcomes of the pathway that are comparable in humans. One important regulatory role of RNAi in fission yeast is to establish and maintain heterochromatin over centromeres, telomeres, and mating loci, as well as transient heterochromatin over convergent genes [28]. The majority of RNAi genes have been shown to be convergent, including $d r 1^{+}, a g o 1^{+}$, and $c / r 4^{+}$, which directly contributes to their role in cell cycledependent formation of heterochromatin in cellular integrity [28]. Their convergent gene pairs are $\mathrm{mmi1}^{+}$, $s p n 6^{+}$, and meu $^{+}$, respectively. All of these genes encode for proteins involved in meiosis, a process in which requires decreased RNAi to allow for a global change in the transcriptome. For example, the convergent gene for $\mathrm{agol}^{+}, \mathrm{mmi1}^{+}$, has roles in chromatin organization and silencing at centromeres, as well as in transcriptional regulation. Transcriptional interference between these convergent genes would allow for decreased RNAi activity when access to these centromeric regions is required.

\subsubsection{Small non-coding RNA (sncRNA)}

There are two classes of non-coding RNA (ncRNA), species that are generally distinguished according to length: small non-coding RNA (sncRNA) species and long non-coding RNA (IncRNA) species. sncRNAs are typically $\leq 200$ nucleotides in length whereas IncRNAs are >200 nucleotides in length [11], [24], [25], [29]. Many different types of sncRNAs and their mechanisms have been studied extensively and are thoroughly characterized. This includes small interfering RNAs (siRNAs), microRNAs (miRNAs), short hairpin RNAs (shRNAs), and several others [24]. sncRNAs typically have direct roles regulating gene expression in a variety of pathways such as stem cell self-renewal and differentiation. In most cases, sncRNAs bind to target messenger RNA (mRNA) either directly (miRNAs) or with the help of RNAi components (siRNAs or shRNAs). However, an indirect role for sncRNAs to alter gene expression has been suggested because of their interactions with other ncRNA [11], [24]. Multiple studies have shown interactions between miRNA and IncRNA that lead to regulation of the ncRNAs themselves in a variety of normal and abnormal cellular processes, such as sexual differentiation and the mammalian epithelialmesenchymal transition (EMT), respectively [24], [30]-[32]. In addition to gene silencing, other sncRNAs such as small nucleolar RNAs (snoRNAs) have roles in sncRNA modifications, namely ribosomal RNAs (rRNAs) and transfer RNAs (tRNAs), which are responsible for translation of mRNAs to proteins.

\subsubsection{Long non-coding RNA (IncRNA)}

Compared to sncRNA, long non-coding RNA (IncRNA) are a newer and emerging class of ncRNAs.

These lack a definitive classification system, since the majority have been identified only through largescale screens and their functionality has not yet been determined [11], [25]. Currently, IncRNAs are categorized based on their relative location to the nearest protein-coding gene; further investigation into 
the functions and regulatory mechanisms may provide a more conclusive grouping [24]. Expression patterns of IncRNAs are exquisite in both a temporal and spatial sense, which allows for the variety of regulatory roles observed in self-renewal, apoptosis, and differentiation pathways, and the implications in controlling commitment and execution of cell-fate programs during development [11], [12], [33].

\subsection{Cell Cycle Checkpoints}

Cell cycle checkpoints monitor the conditions of a cell, such as genomic stability and DNA integrity, throughout cellular division. Mechanisms are in place at each stage of the cell cycle to prevent progression to subsequent stages when favourable conditions are not met.

\subsubsection{Overview of Checkpoint Mechanisms}

The G1/S checkpoint in G1 phase ensures sufficient cell growth, the intra-S phase or DNA replication checkpoint in S phase prevents errors in DNA replication, the G2/M or DNA damage checkpoint in $\mathrm{G} 2$ phase restricts division in the presence of damaged DNA, and the spindle assembly checkpoint in $\mathrm{M}$ phase confirms attachment of chromosomes to spindle for correct chromosome segregation in mitosis. Checkpoint control is mediated by a family of protein kinases, cyclin-dependent kinases or CDKs, that phosphorylate their substrates on serine and threonine amino acid residues, making them serinethreonine kinases [34], [35]. The CDKs and other checkpoint proteins, along with the mechanisms governing activation/regulation are highly conserved in most organisms including yeast and humans; the homologues of the various proteins can be seen in Table 2.1.

Table 2.1 Conserved checkpoint protein homologues

\begin{tabular}{|c|c|c|c|}
\hline Protein & S. pombe & S. cerevisiae & Human \\
\hline Apical Kinase & Rad3 ${ }^{\text {ATR }}$ & Mec1 & ATR \\
& Tel1 ${ }^{\text {ATM }}$ & Tel1 & ATM \\
\hline Mediators & Crb2 & Rad9 & 53BPI \\
& Mrc1 & Mrc1 & CLASPIN \\
\hline Effector Kinase & Chk1 & Chk1 & CHK1 \\
& Cds1 & Rad53 & CHK2 \\
\hline CDK & Cdc2 & Cdc28 & CDK1 \\
\hline CDK Activator & Cdc25 & Mih1 & CDC25B \& CDC25C \\
\hline CDK Inhibitor & Wee1 & Swe1 & WEE1 \\
\hline Sensors & Mre11-Rad50-Nbs1 & Mre11-Rad50-Xrs2 & MRE11-RAD50-NBS1 \\
\hline
\end{tabular}




\subsubsection{Role(s) of DNA Damage Checkpoint}

The DNA damage checkpoint is activated in response to double stranded breaks (DSBs) in DNA through an increase in single stranded DNA (ssDNA). Elevated levels of ssDNA resulting from DSBs are recognized by the Mrc11-Rad50-Nbs1 (MRN) complex, which recruits the apical kinase, Rad3 ${ }^{\text {ATR }}$ [36]-[38]. If the ssDNA was bound to the Replication Protein A (RPA) complex due to problems during replication, it would instead be recognized by the Rad9-Hus1-Rad1 (9-1-1) complex, which would then recruit Rad3 ${ }^{\text {ATR }}$ [39]. Depending on whether it is a resected break (DSB repair, DSBR) or ssDNA-RPA-9-1-1 (replication instability), Rad3 ${ }^{\text {ATR }}$ and adaptor protein Rad26 ${ }^{\text {ATRIP }}$ (ATR interacting protein, ATRIP) phosphorylates the appropriate effector kinase to activate either the DNA damage or DNA replication signaling cascade (see Fig 2.2). The S. pombe DNA damage checkpoint is characterized by phosphorylation of the effector kinase Chk1 by the Rad3 ${ }^{\text {ATR }}$-Rad26 ATRIP complex, with the help of mediator protein Crb2 ${ }^{53 \text { BPI }}$ [36], [37], [40]. Chk1 has an important role in DNA damage checkpoint as the regulator of the cycle-dependent kinase, Cdc2, governing the transition from $\mathrm{G} 2$ to $\mathrm{M}$ phase of the cell cycle. When activated, the cell cycle pauses to allow for DNA damage repair. Once damage has been corrected, progression into mitosis requires inactivation and/or suppression of Chk1.

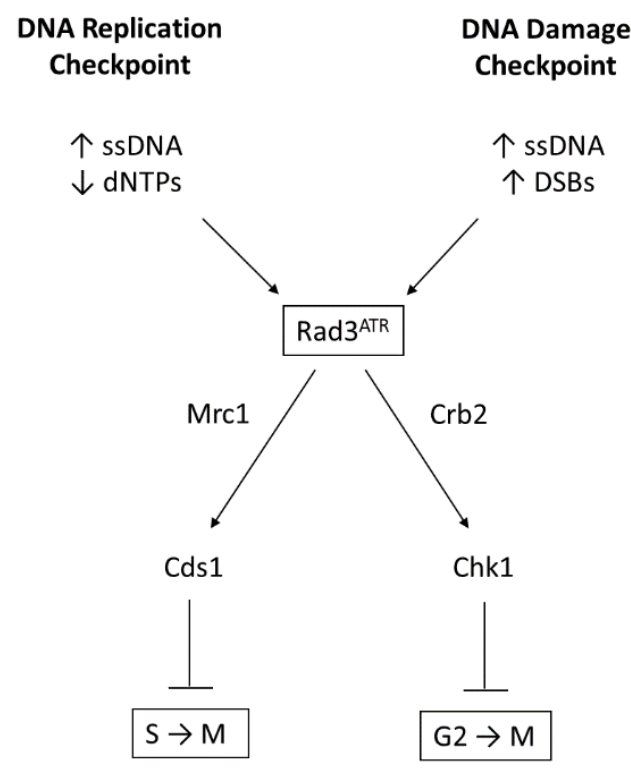

Figure 2.2 DNA damage and DNA replication checkpoint kinase cascades

Signals transmitted to the master regulator, Rad3 ${ }^{A T R}$, are amplified through downstream effector kinases in either the DNA damage or DNA replication checkpoint pathways to arrest the cell cycle. Chk1 controls the transition from G2-M. Cds1 is activated during replication instability as a part of the intra-S or S-M checkpoint, both of which prevent mitotic entry in the presence of under-replicated DNA. 
Additional factors regulate Chk1 recruitment and phosphorylation to promote targeted and appropriate DSBR activation. For example, the Rad4 ${ }^{\text {TOPBP1 }}$ protein is a scaffold that links Rad3 to Crb2 and Chk1, promoting phosphorylation by proximity [41]. Chk1 recruitment is further regulated by histone modifications. The dominant marker of DSBs is histone H2A serine 129 phosphorylation ( $\mathrm{pH} 2 \mathrm{~A})$, analogous to phosphorylation of serine 139 in human H2A.X [42], [43]. Histone H4 epigenetic marks also contribute to Chk1 recruitment and checkpoint activation at telomeres, preventing incorrect activation [44]-[46]. These multiple layers of Chk1 regulation and recruitment propose that Chk1 is a powerful director of checkpoint activity and cell fate. Chk1 has an important role as the link to Cdc2, the CDK that allows entry into mitosis [40], [47]. Cdc2 is controlled by the antagonistic activities of the Wee1 kinase (CDK inhibitor) and Cdc25 phosphatase (CDK activator), both of which are influenced by Chk1 [3], [47], [48]. Activation of Chk1 promotes phosphorylation of Wee1, causing inhibition of Cdc2, which results in G2-M arrest. As Wee1 is activated, Cdc25 is inhibited and can no longer activate Cdc2, which would allow the cell cycle to progress to mitosis.

Absolute levels of Chk1 protein are important to cell health. When Chk1 is absent (chk1 1 mutant cells), cells appear phenotypically normal until a DNA damaging agent is encountered. The chk1 $\Delta$ mutant cells are incapable of arresting the cell cycle in response to DSBs and enter mitosis despite DNA damage [49]. The premature mitosis is lethal and causes a classical cell cycle morphology known as cell untimely torn, or "cut" [50]. Too much Chk1 is also problematic, as Chk1 overexpression leads to its autophosphorylation which ectopically activates DSBR pathway components in the absence of DNA damage [51]. Overexpression of $c h k 1^{+}$causes cell elongation as Cdc2 becomes phosphorylated while cells continue to grow in $\mathrm{G} 2$ but cannot overcome the block to mitosis.

With Chk1 having an essential role in controlling cell division it has become a protein of interest in cancer drug targeting treatment [35]. The Sabatinos Lab is investigating the modulation of the DNA damage checkpoint in response to environmental stress and chemotherapeutic drugs. Our goal is to better understand the mechanisms involved in activation or inhibition of checkpoint under external stressors, which may lead to improved drug targeting of diseases with abnormal checkpoint regulation.

\subsubsection{Convergent Gene Pairs and Checkpoint Proteins}

In fission yeast, 30 of the $47 \mathrm{GO}$-term checkpoint genes are convergent with other protein-coding genes, some of which are involved in DNA replication, meiosis, or even the RNAi pathway [28], [52]. Many of these convergent protein-coding genes are stress-inducible, suggesting a novel mechanism for 
checkpoint regulation. In the DNA damage checkpoint alone, several of the genes are convergent, including $\mathrm{rad}^{+}, \operatorname{rad}_{26} 6^{+}, \operatorname{chk} 1^{+}, \mathrm{crb2} 2^{+}$, and $c d c 2^{+}$, which produce the respective proteins of the same name (Fig A1, Appendix A). The convergent gene pairs of $\mathrm{rad}^{+}$and $\mathrm{rad}_{26} 6^{+}$are swi1 $^{+}$and $a t d 1^{+}$, which code for the proteins Swi1 and Atd1, respectively. Swi1 is a component of the DNA replication fork protection complex, forming a physical bridge between the helicase and polymerase subunits. Swi1 contributes to the activation of DNA replication checkpoint during replication fork arrest. Atd1 is an aldehyde dehydrogenase that responds to the presence of acetaldehyde that can be disruptive during replication [53], [54]. $c r b 2^{+}$is convergent with $r t t 109^{+}$, and $c d c 2^{+}$is convergent with $p h t 1^{+}$, both of which code for proteins involved in maintaining genome stability. The Rtt109 protein recruits histone chaperones for the acylation of histone H3 Lys56, essential also in DNA damage responses [55]. On the other hand, pht1 ${ }^{+}$ codes for the histone variant H2A.Z that is inserted and acetylated during anaphase; mutations in H2A.Z result in chromosome entanglement and even breakage [56].

\subsubsection{A Specific Example: $\operatorname{chk} 1^{+}$and $m e u 27^{+}$}

The gene converging with $c h k 1^{+}$is $m e u 27^{+}$(Fig. A1, Appendix A), which produces a meiotic expression upregulated protein, Meu27, that was first detected during a meiotic screen in S. pombe in 2001 [57]. No homologues of this protein have been identified, nor has its function been characterized. According to the visual analysis of a genome-wide gene deletion library in S. pombe, meu27 $\Delta$ mutant cells appear phenotypically normal during mitotic/vegetative growth and are apparently normal during meiosis [58]. Recent affinity capture-MS and synthetic genetic array analyses suggest that Meu27 has genetic and/or physical interactions with ATP-dependent DNA helicase Fft1, and the beta subunit of AMPactivated protein kinase (AMPK), Amk2, respectively [59], [60].

This convergent gene pair is situated just upstream of the centromere on Chromosome III. Facultative heterochromatin islands at meiotic genes have been mapped near this location and have been shown to disassemble during sexual differentiation in response to nutritional signals [61]. This suggests that this area responds to environmental cues which modulate gene expression.

\subsection{Hypotheses}

To date, convergent transcription-interference mechanisms have not been implicated in checkpoint modulation. It remains unclear whether the convergent promoter orientation of the many DNA damage checkpoint genes alters their expression or checkpoint activity. Furthermore, the capacity at which environmental stress can impact checkpoint regulation through convergent transcription is 
unknown. While meiosis represents a specific cell differentiation pathway, more general modes of environmental stress may also regulate transcription and cell fate. In particular, we recognize that meiosis in fission yeast is initiated through nutrient loss. Nitrogen depletion plays a critical component in promoting cell quiescence and entry into meiosis. Additionally, the majority of yeast experiments are performed under synchronous conditions using the pat1-114 temperature sensitive allele. These experiments involve a combination of general nutrient-depletion, nitrogen-depletion, and temperature stress to cause all cells in the culture to enter meiosis at the same time. Therefore, meiotically-regulated genes may also be regulated by mitotic stress. We hypothesize that convergent transcription mechanisms regulate checkpoint expression and/or activation under mitotic stress. Our main goal is to investigate the transcription-interference mechanism(s) influencing $c h k 1^{+}$in response to activation of the convergent gene pair, $\operatorname{meu} 27^{+}$.

\subsection{Specific Aims}

- Determine convergent transcriptional effects on $c h k 1^{+}$expression

- Analyze the potential for checkpoint regulation through convergent transcription

- Explore the influence of environmental stress on checkpoint 


\section{Chapter 3:}

\section{Materials and Methods}

This chapter provides a detailed outline of the experimental setup for methods used throughout this study to test our hypotheses.

\subsection{Yeast Strains and Growth Media}

S. pombe "lab strains" were kindly provided by Susan Forsburg of the University of Southern California (Los Angeles, CA USA) and are outlined alongside constructed strains in Table 3.1. Strains were grown in a rich medium, yeast extract with supplements (YES), at $30^{\circ} \mathrm{C}$ unless otherwise indicated.

Table 3.1 Yeast strains used in this research project

\begin{tabular}{|c|c|c|}
\hline Strain No. & Genotype & Source \\
\hline FY 435 & $h^{+}$ade6-M210 his7-366 leu1-32 ura4-D18 & Lab Strain \\
\hline FY 436 & $h^{-}$ade6-M216 his7-366 leu1-32 ura4-D18 & Lab Strain \\
\hline FY 5149 & $\begin{array}{c}h^{+} \text {chk1D::ura4 }{ }^{+} \text {leu1-32::hENT1-leu1 }{ }^{+}(p J A H 29) \text { his7-366::hsv-tk- } \\
\text { his } 7^{+}(p J A H 31) \text { ura4-D18 ade-704 }\end{array}$ & Lab Strain \\
\hline SASY 94 & $h^{-}$chk1-HA(ep) ade6-M216 leu1-32 ura4D-18 & Lab Strain \\
\hline SASY 133 & $h^{-}$ade6-M210 & Lab Strain \\
\hline SASY 161 & $h^{+}$Pmeu270::KanMX chk1-HA(ep) ade6-M216 his7-366 leu1-32 ura4-D18 & This Study \\
\hline SASY 162 & h- Pmeu27士::KanMX chk1-HA(ep) ade6-M216 his7-366 leu1-32 ura4-D18 & This Study \\
\hline SASY 163 & $h^{+}$Pmeu270::KanMX chk1-HA(ep) ade6-M210 his7-366 leu1-32 ura4-D18 & This Study \\
\hline SASY 164 & h- Pmeu27士::KanMX chk1-HA(ep) ade6-M210 his7-366 leu1-32 ura4-D18 & This Study \\
\hline SASY 202 & $h^{+}$meu27-FLAG::urg1::KanMX chk1-HA(ep) ade6-M216 his7-366 leu1-32 & This Study \\
\hline SASY 203 & h' meu27-FLAG::urg1::KanMX chk1-HA(ep) ade6-M216 & This Study \\
\hline SASY 204 & $h^{+}$chk1+>>KanMX $>><<$meu27 ${ }^{+}$ade6-M216 his7-366 leu1-32 ura4-D18 & This Study \\
\hline SASY 205 & $h^{-}$chk1+ $1^{+}>$KanMX $>><<m e u 27^{+}$ade6-M216 his7-366 leu1-32 ura4-D18 & This Study \\
\hline
\end{tabular}

\subsection{Plasmids and Primers}

\subsubsection{Plasmids}

DNA fragments generated by the polymerase chain reaction (PCR)-based gene targeting method (described in section 3.3.1) resulted from two different plasmid templates. Plasmids were obtained from Addgene.org. The insert for the meu $27^{+}$promoter knockout and the $c h k 1^{+}>>\operatorname{KanMX}>><<\operatorname{meu} 27^{+}$broken convergence strains used the plasmid pFA6a-KanMX6, a gift from Jürg Bähler and John Pringle (Addgene plasmid \#39296; http://n2t.net/addgene:39296; RRID:Addgene_39296) [62]; the insert for the meu27 
overexpression strain used the plasmid pFA6a-KanMX6-Purg1-3FLAG, courtesy of Eishi Noguchi (Addgene plasmid \#19354; http://n2t.net/addgene:19354; RRID:Addgene_19354) [63].

\subsubsection{Primers}

Primers were designed as outlined in [62], [63]. Hybrid sequences containing an adapter sequence for the plasmid along with locus specific segments were designed de novo using ApE - A Plasmid Editor software (http://biologylabs.utah.edu/jorgensen/wayned/ape), shown in Table 3.2.

Table 3.2 Primers used for strain construction

\begin{tabular}{|c|c|}
\hline Name & Sequence \\
\hline \multicolumn{2}{|r|}{ meu $27^{+}$promoter delete } \\
\hline UP forward & $5^{\prime}-$ CCAGGATGCAAATGGTTAGC - 3' \\
\hline UP reverse & $5^{\prime}$ - ggggatccgtcgacctgcagcgtacgaCTTGAGTGATTGCCAGTTGG - 3' \\
\hline DWN forward & 5'-gtttaaacgagctcgaattcatcgatCCAAGTAACTTCGTAATGAACAG - 3' \\
\hline DWN reverse & 5' - CCTTTGAAGGATTTTGGTTTGA - 3' \\
\hline \multicolumn{2}{|r|}{ meu27 ${ }^{+}$overexpression } \\
\hline UP forward & 5' - CCAGGATGCAAATGGTTAGC - 3' \\
\hline UP reverse & 5' - gtttaaacgagctcgaattcCTTGAGTGATTGCCAGTTGG - 3' \\
\hline DWN forward & $\begin{array}{l}5^{\prime} \text { - ctataaggacgatgatgataaaggaggcggaAACAGTAAAATTGCTTATCCAGAG - } \\
3^{\prime}\end{array}$ \\
\hline DWN reverse & 5' - CCTTTGAAGGATTTTGGTTTGA - 3' \\
\hline \multicolumn{2}{|r|}{ chk1 $/$ meu27 $7^{+}$broken convergence } \\
\hline UP forward & 5' - GGGGATCCTCTTGAATGGAG - 3' \\
\hline UP reverse & $5^{\prime}$ - ggggatccgtcgacctgcagcgtacgaCAATGGTTGCGAATGCTGAAG - 3' \\
\hline DWN forward & $5^{\prime}$ - gtttaaacgagctcgaattcatcgatATCCTATTCCCTAGGATATCA - 3' \\
\hline DWN reverse & 5' - CTACATTGATAAGTACTGGTTC - 3' \\
\hline
\end{tabular}

\subsection{Strain Construction}

\subsubsection{Polymerase Chain Reaction (PCR)-Based Gene Targeting}

This well-established two-step PCR-based method for S. pombe gene editing uses four small primers (UP forward and reverse and DWN forward and reverse; Table 3.2) to generate two primers with long tracks of homology flanking the insertion site. These long primers are then used to incorporate the desired gene from the plasmid into the DNA sequence of the yeast through PCR amplifiacation [62].

\subsubsection{Diploid Isolation}

Two S. pombe strains of opposite mating type $\left(h^{+}\right.$and $\left.h^{-}\right)$and complementary intragenic markers (in this case, the ade6 alleles) were crossed on extremely low nitrogen plates (ELN; EMM with $1 \mathrm{~g} / \mathrm{L} \mathrm{NH}_{4} \mathrm{Cl}$ 
and $225 \mathrm{mg} / \mathrm{L}$ adenine, leucine, histidine, and uracil) and incubated for $16-24 \mathrm{~h}$ at room temperature (RT). Crosses were screened on plates containing EMM and supplements histidine, uracil, and leucine (EMM+HUL; $5 \mathrm{~g} / \mathrm{L} \mathrm{NH}{ }_{4} \mathrm{Cl}$ and $225 \mathrm{mg} / \mathrm{L}$ leucine, histidine, and uracil). The absence of adenine in the media selected for ade6-M210/ade6-M216 diploids that were viable due to the presence of the complementing ade6 alleles. Diploids were then grown on YES with Phloxin B stain to confirm a darker pink stain compared to haploid cells. Protocol described in [64].

\subsubsection{Electroporation}

Diploids from 3.3.2 were grown in $\mathrm{EMM}+\mathrm{HUL}$ at $30^{\circ} \mathrm{C}$ to mid-log phase and harvested by centrifugation for $5 \mathrm{~min}$ at $1500 \mathrm{rpm}, 4^{\circ} \mathrm{C}$. To render cells electrocompetent, pellets were washed in $1 / 2$ volume cold, sterile Milli $\mathrm{Q}$ water followed by $1 / 4$ volume cold, sterile $1 \mathrm{M}$ sorbitol. Final resuspension was $\sim 100 \mu \mathrm{L} / 0.1 \mathrm{OD}_{600}$ in $1 \mathrm{M}$ sorbitol. For each transformation, $40 \mu \mathrm{L}$ of cell suspension was electroporated with up to $1 \mu \mathrm{g}$ of integration fragment DNA generated from the PCR-based gene targeting method described in 3.3.1. Chilled $2.0 \mathrm{~mm}$ gap electroporation cuvettes were used (BioRad). A BioRad electroporator module was set to $1500 \mathrm{~V}$ and $25 \mu \mathrm{F}$, and the time constant was recorded to monitor electroporation uniformity. Cells were transferred from the cuvette using $1 \mathrm{~mL}$ of $1 \mathrm{M}$ sorbitol, centrifuged at $5000 \mathrm{rpm}$ for $5 \mathrm{~min}$ and washed with $1 \mathrm{~mL}$ Milli Q water. Pelleted, transformed cells were resuspended in $100 \mu \mathrm{L}$ Milli Q water, plated on a $10 \mathrm{~cm}$ YES agar plate, and incubated overnight at $30^{\circ} \mathrm{C}$. After $24 \mathrm{~h}$, cells were replica plated from YES onto selective media (YES-G418) to isolate candidates for screening. Following initial selection on YES-G418, resistant colonies were grown on YES without drug to relax selection and screen for stable integrants. These stable G418-resistant isolates were further investigated to confirm construct integration using replica plate phenotyping, PCR, and western blot methods, as required.

\subsubsection{Random Spore Analysis (RSA)}

Candidates for strain construction were crossed on ELN at RT for 3-4 days to allow for sporulation. Asci from these crosses were then incubated in a $0.5 \%$ glusulase solution (PerkinElmer \#NEE154001) overnight at RT. In the case of diploid integration isolates, cells were incubated on ELN for $16-24 \mathrm{~h}$ to complete meiosis before resuspension in glusulase and overnight incubation. Spore concentrations were counted using a hemocytometer and $250-500$ spores were plated onto a YES plate, then grown for 3-4 days at $30^{\circ} \mathrm{C}$. Colonies were replica plated to test for selective markers to determine candidates for further analysis. Refer to [64] for detailed protocol. 


\subsubsection{Backcrossing Strains}

Selected strain construction candidates were crossed against a known wild-type strain, followed by RSA, as outlined in 3.3.4. Resulting spores were analyzed for G418 resistance to determine the appropriate segregation ratio and/or screened for a new desired phenotype.

\subsubsection{Mating Type Testing by Iodine (I/2) Staining}

Candidate colonies were patched onto an ELN plate and crossed with wild-type strains of each known mating type. Plates were incubated at RT for 3-4 days before exposure to iodine $\left(I_{2}\right)$ crystals for 1020 minutes. The $I_{2}$ vapour stains the starch of the spore walls and appears dark, indicating mating. Identification of the mating type of the candidate colony is inferred by successful mating with a known wild-type strain.

\subsection{DNA Staining}

Cells were fixed with cold $70 \%$ ethanol, vortexed, and stored at $4^{\circ} \mathrm{C}$. To prepare for imaging, $\sim 250 \mu \mathrm{L}$ of fixed cells were washed twice with $1 \mathrm{~mL}$ water. The pellet was resuspended in $20-50 \mu \mathrm{L}$ water and mounted on a slide $(3 \mu \mathrm{L})$. For DNA staining, $4 \mu \mathrm{L}$ of DAPI solution containing DABCO mount media was placed directly on sample and covered with a coverslip. Refer to [64] for full protocol. Slides were stored at $-20^{\circ} \mathrm{C}$. Images were taken using an Olympus Deconvolution Microscope with a UV excitation source at a magnification of 60X; spore formation and DNA segregation was analyzed using Fiji (ImageJ) software.

\subsection{Western Blot}

\subsubsection{TCA Total Protein Extraction}

Yeast cultures were harvested by centrifugation $\left(1700 \mathrm{rpm}, 5 \mathrm{~min}, 10^{\circ} \mathrm{C}\right)$ and pellets were washed with water. Samples stored at $-80^{\circ} \mathrm{C}$ before proceeding to TCA protocol; pellets thawed to RT. Cells were resuspended in 20\% TCA and lysed with glass beads in a FastPrep cell homogenizer. Supernatant was diluted to a concentration of $10 \%$ TCA and collected by centrifugation (1500 rpm, $\left.5 \mathrm{~min}, 10^{\circ} \mathrm{C}\right)$. Precipitated protein was then pelleted by centrifugation $(13,300 \mathrm{rpm}, 10 \mathrm{~min}, \mathrm{RT})$ and stored at $-80^{\circ} \mathrm{C}$.

\subsubsection{SDS-PAGE \& Immunoblotting}

To prepare samples for gel electrophoresis, pellets were resuspended in SDS buffer (50mM Tris $\mathrm{pH} 6.8,2 \%$ SDS, $10 \%$ glycerol, $1 \% \beta$-mercaptoethanol, 12.5mM EDTA, $0.02 \%$ bromophenol blue) and boiled at $100^{\circ} \mathrm{C}$ for 5 minutes. Proteins were run on an $8 \%$ gel and transferred to a PVDF membrane at 
$40 \mathrm{~V}$ for $1 \mathrm{~h}, 50 \mathrm{~V}$ for $15 \mathrm{mins}$ (BioRad apparatus). A $5 \%$ milk in PBS-T buffer was used to block proteins for $1 \mathrm{~h}$ at RT. Blots were probed with anti-FLAG (1:1000) or anti-HA (1:500) primary antibody overnight at $4^{\circ} \mathrm{C}$ and probed with an anti-HRP linked (1:5000) secondary antibody for $1 \mathrm{~h}$ at RT; that antibody was then stripped, and the blot was probed again with the alternate primary antibody. Bands were detected using an ECL solution (BioRad) on a ChemiDoc system.

\subsection{Nitrogen Starvation}

Cultures of EMM with supplements $\left(5 \mathrm{~g} / \mathrm{L} \mathrm{NH}_{4} \mathrm{Cl}\right.$ and $225 \mathrm{mg} / \mathrm{L}$ histidine, leucine, adenine, with or without uracil) were incubated overnight at $30^{\circ} \mathrm{C}$ with shaking, and then allowed to incubate at RT throughout the day (total $\sim 24 \mathrm{~h}$ ). Asynchronous samples in mid-log phase were harvested by centrifugation (1700rpm, $5 \mathrm{~min}, 4^{\circ} \mathrm{C}$ ) for RNA and flow cytometry. Remaining cultures were pelleted, washed twice with water, and resuspended in an equal volume of EMM without nitrogen, plus $75 \mu \mathrm{g} / \mathrm{mL}$ of appropriate supplements. Cultures were incubated for $16 \mathrm{~h}$ at $25^{\circ} \mathrm{C}$. An equal volume of EMM, with $255 \mathrm{mg} / \mathrm{mL}$ supplements and $5 \mathrm{~g} / \mathrm{L}$ nitrogen, was then reintroduced to the cultures. Samples were immediately harvested for RNA and flow cytometry while remaining cultures were incubated at $30^{\circ} \mathrm{C}$ before harvest at $2 \mathrm{~h}$ and $4 \mathrm{~h}$ timepoints. Pellets for RNA were stored at $-80^{\circ} \mathrm{C}$ and those for flow cytometry were fixed in $70 \%$ ethanol and stored at $4^{\circ} \mathrm{C}$; refer to sections $\mathbf{3 . 7}$ and $\mathbf{3 . 8}$ for detailed flow cytometry and RT-qPCR preparations, respectively.

\subsection{Flow Cytometry}

Sample preparation was carried out as outlined in [64]. Ethanol-fixed cells (in $70 \%$ ethanol) were pelleted and washed twice with $1 \mathrm{~mL} 0.5 \mathrm{mM}$ sodium citrate, vortexing well between each wash. Cells were resuspended in $0.5 \mathrm{~mL}$ of a $0.5 \mathrm{mM}$ sodium citrate solution containing $0.1 \mathrm{mg} / \mathrm{mL}$ RNase $A$ and incubated at $37^{\circ} \mathrm{C}$ for $2 \mathrm{~h}$. An equal volume of $0.5 \mathrm{mM}$ sodium citrate containing $1 \mu \mathrm{M}$ Sytox Green was added, then samples were vortexed and incubated for $30 \mathrm{~min}$ at $4^{\circ} \mathrm{C}$. A Becton Dickenson (BD) Accuri C6 Plus flow cytometer was used to measure the DNA content of samples; data was analyzed using FlowJo (TreeStar) software.

\subsection{Quantitative Reverse Transcription PCR (RT-qPCR)}

Yeast cultures were harvested by centrifugation (1700rpm, $5 \mathrm{~min}, 4^{\circ} \mathrm{C}$ ) and pellets of 1 to $5 \times 10^{6}$ cells were washed with water then stored at $-80^{\circ} \mathrm{C}$. Total RNA extraction was carried out using glass bead 
lysis in a FastPrep cell homogenizer and RNeasy Mini Kit (QIAGEN). Purified RNA was eluted in RNase-free water and concentrations were recorded with the use of a Nanodrop. RNA samples were stored at $-80^{\circ} \mathrm{C}$. RNA was diluted to $\sim 10 \mathrm{ng} / \mu \mathrm{L}$ in RNase-free water before use and kept on ice during reaction set-up. Luna Universal One-Step RT-qPCR kit (New England Biolabs) protocol was used. Reactions were set up in

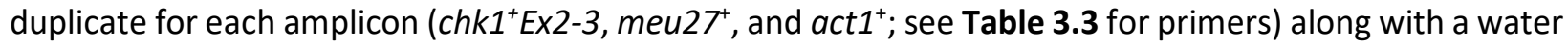
control (no RNA) and no RT enzyme control. A master mix for the appropriate number of reactions (samples, in duplicate) per amplicon, plus an additional 10\%, was prepared and pipetted into a 96-well plate. RNA templates and water controls were added separately. CFX96 Touch Real-Time PCR detection system was programmed with the appropriate thermocycling protocol (Fig 3.1). A relative quantification of data was conducted using the $2^{-\Delta \Delta C T}$ method. This common method uses the $C T$ (threshold cycle; cycle at which the fluorescence threshold is reached) information generated from the qPCR detection system to calculate target gene expression levels relative to a reference gene and normalizer [65], in this case the wild-type strain and housekeeping gene, actin, respectively.

Table 3.3 Primers for amplicons of RT-qPCR protocol

\begin{tabular}{|c|c|c|}
\hline Amplicon & Primer & Sequence \\
\hline \multirow{2}{*}{ chk1+Ex2-3 } & Forward & 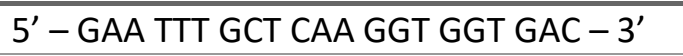 \\
\hline & Reverse & $5^{\prime}$ - TCA GGT TTC AAG TCT CGA TGC - 3' \\
\hline \multirow{2}{*}{$\operatorname{meu} 27^{+}$} & Forward & $5^{\prime}$ - GGA ATC AGA ACT CCA GAC GAA A - 3' \\
\hline & Reverse & 5' - TGC GGA TGT AAC CTG ACT AAT G - 3' \\
\hline \multirow{2}{*}{$\operatorname{act1}^{+}$} & Forward & $5^{\prime}-$ TGA ACC CCA AAT CCA ACC G - 3' \\
\hline & Reverse & $5^{\prime}$ - CAC CAT CAC CAG AGT CCA AG - 3' \\
\hline
\end{tabular}

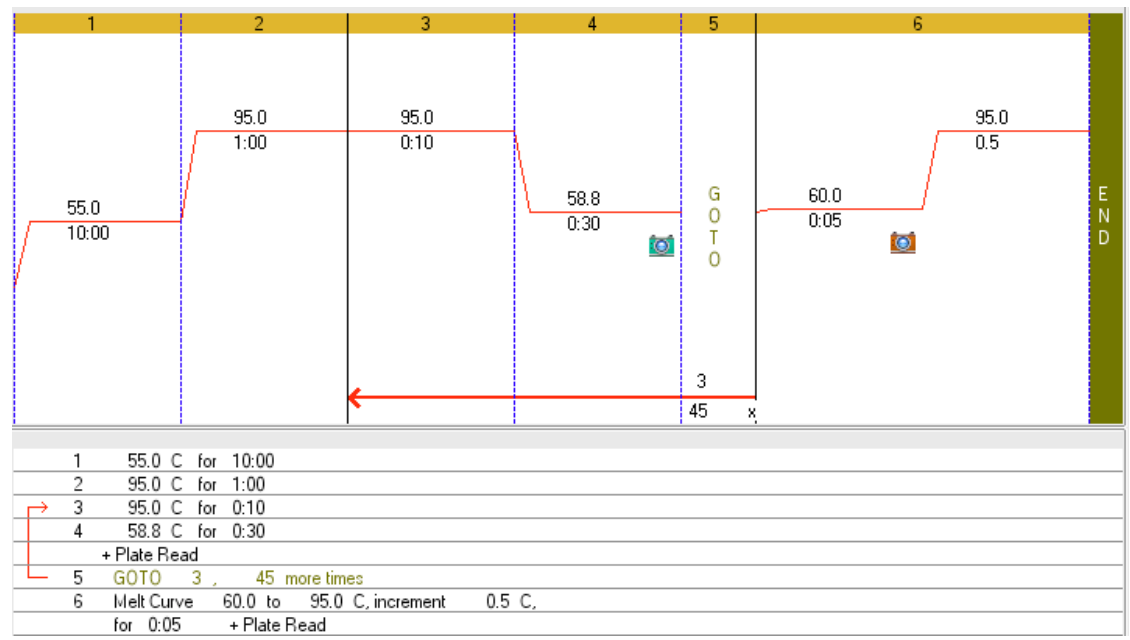

Figure 3.1 RT-qPCR Thermocycling Protocol

CFX96 Touch Real-Time PCR Thermocycler settings. Cycle steps (1 - reverse transcription, 2 - initial denaturation, 3 -denaturation, 4 - extension, 5 -cycles, 6 -melt curve), temperature $\left({ }^{\circ} \mathrm{C}\right)$, duration ( $\left.\min \right)$, and number of cycles for each reaction step. 


\section{Chapter 4:}

\section{Results}

This chapter presents the experimental setup and main findings of the research conducted to investigate the hypotheses and specific aims outlined in sections 2.6 \& 2.7, respectively.

\subsection{Strain Construction}

Deletion and overexpression of genes are imperative in functional analyses to characterize a gene of interest, therefore, several simple and versatile methods for genetic manipulation of $S$. pombe have been established [62], [66]. A PCR-based gene targeting method (section 3.3; detailed in [62]) was used in this study to construct three strains to investigate the convergent transcriptional effect(s) of meu27 on $c h k 1^{+}$. The first strain constructed was a promoter deletion of meu27 $7^{+}$(Pmeu27A), with the insertion of a reporter gene, KanMX6, between the promoter and coding sequence of the gene (Fig 4.1, A \& B). The convergent orientation and overlapping complementary sequences were maintained. Next, was the construction of a strain to overexpress $m e u 27^{+}\left(m e u 27^{+} O E\right)$, with an exogenous uracil responsive promoter, urg1 (Fig. 4.1, C). In addition, a strain was designed to break potential convergent relationships between the $c h k 1^{+}$and $m e u 27^{+}$genes with the insertion of the KanMX6 reporter gene between the two transcriptional units, $c h k 1^{+}>>K a n M X>><<m e u 27^{+}$, referred to as $c h k 1^{+} / \operatorname{meu} 27^{+}$(Fig 4.1, D). Successful integration was confirmed by PCR and western blot (where applicable) for all strains (Appendix B).

Chk1-HA was used as the parent strain for Pmeu27 $\triangle$ and meu27+OE, whereas, the wild-type strain was used for $c h k 1^{+} /$meu $27^{+}$. The HA tag on Chk1 was situated just upstream of the $c h k 1^{+}$stop codon and was shown not to interfere with the function of the protein [51]. The location of the HA tag insertion does not interfere with the convergent nature of $c h k 1^{+}$and $m e u 27^{+}$as it is the $3^{\prime}$ UTR of $c h k 1^{+}$that overlaps entirely with meu $27^{+}$which retains the complementarity of the RNA transcripts.

\subsection{A meu $27^{+}$promoter deletion strain $(\operatorname{Pmeu} 27 \Delta)$}

\subsubsection{Pmeu27 $\Delta$ phenocopies $\operatorname{chkI^{+}}$ overexpression during meiosis}

Constitutive overexpression of $c h k 1^{+}$in $S$. pombe delays mitotic cell-cycle progression causing elongated cells [49], [67]. In meiosis, chk1+ overexpression causes abnormal chromosome segregation patterns resulting in more or less than the four haploid spores typical of normal meiosis (Sabatinos \& Forsburg, in prep). Meiotic Chk1 overexpression also slows meiotic progression; cells take approximately 
1 hour longer to progress from the first to second meiotic anaphase compared to overexpression controls (Sabatinos \& Forsburg, in prep). We hypothesize that Pmeu27 $\Delta$ cells cannot regulate $c h k 1^{+} \mathrm{RNA}$ expression resulting in higher levels and displaying a phenotype similar to chk1 $1^{+}$overexpression. To confirm, we crossed strains of opposite mating type on ELN to promote conjugation and meiosis. Crosses consisted of:

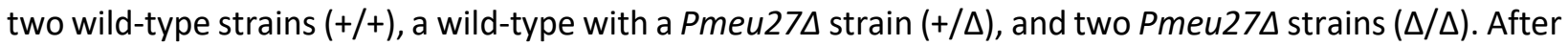
48- and 72-hours DNA was stained with DAPI (section 3.4) and images were taken for visual analysis of meiotic progression and chromosome mis-segregation events.

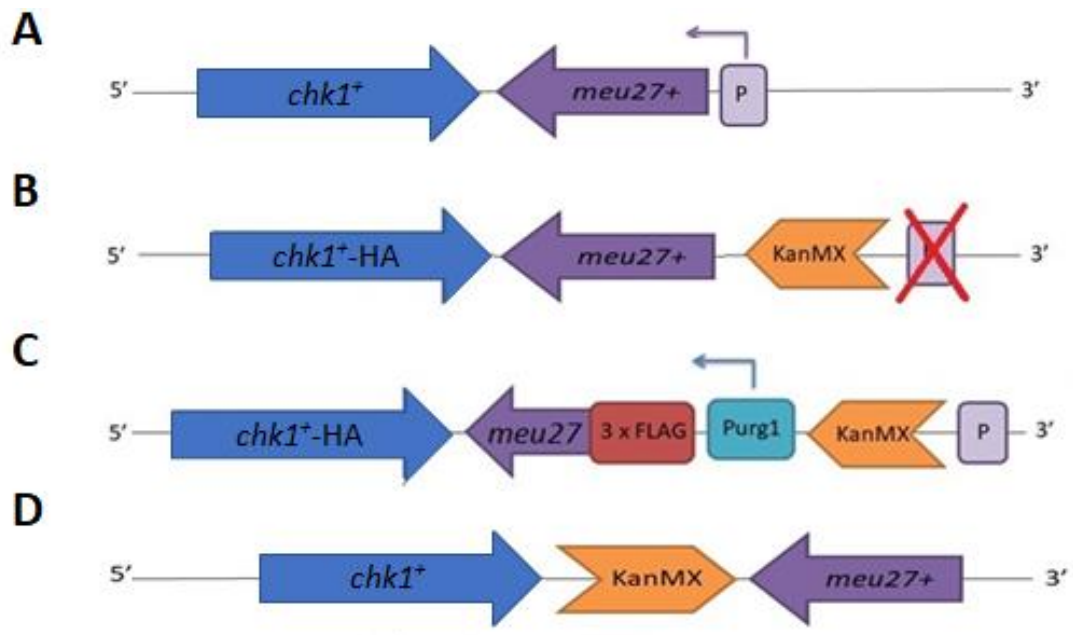

Figure 4.1 Schematic of constructed S. pombe strains

New strains containing integration fragments from various $\mathrm{pFA6a}$ plasmids incorporated into the genome. A. Wild-Type; B. meu $27^{+}$promoter disruption, Pmeu274; C. meu27 $7^{+}$overexpression, meu27OE; D. $c h k 1^{+}>>K a n M X>><<m e u 27^{+}$broken transcriptional unit, chk1 $1^{+} / m e u 27^{+}$. Images are not to scale or proportional. See Appendix A-C for amino acid sequences.

Meiotic events were counted and categorized as "early" or "late" to determine if the Pmeu27 strains $(161,162,163$, and 164; see Table 3.1) cause a delay in meiotic progression. Early meiosis refers to any meiotic product up to and including the first anaphase in Meiosis I; Late meiosis consists of meiotic products from the second anaphase in Meiosis II through sporulation. After 48-hours the total number of meiotic events differs significantly between strains (Fig $4.2 \mathrm{~A}$ ). In the wild-type cross and the second Pmeu27 heterozygote cross, $163 \times \mathrm{WT}$, approximately $6-7 \%$ of their total population is in meiosis. In contrast, one double mutant strain, $161 \times 164$, has only $3 \%$ in meiosis, primarily early meiosis. Interestingly, both strains containing isolate 162 of Pmeu27D (162x163 and 162xWT) have a considerably higher total population in meiosis, $9 \%$ and $13 \%$, respectively. In addition, the heterozygous crosses (Pmeu27 $\mathrm{x}$ WT) and the Pmeu27 homozygote $162 \times 163$ have increased late meiotic events compared to wild-type. 
At 72-hours, meiotic cells are largely in late meiosis, and the total number of meiotic events has increased for all strains (Fig 4.2 B). Once again, wild-type and 163xWT are very similar with approximately the same total percent of their populations in meiosis and between early and late meiotic events. This is not the case with either cross involving Pmeu27D-162; the total number of meiotic events is increased but the number of cells in early meiosis has decreased to a level comparable to that of the Pmeu27D double mutants, $162 \times 163$ and $161 \times 164$. The double mutant $161 \times 164$ has the lowest percent of cells in meiosis, which was expected from homozygote crosses lacking meu $27^{+}$entirely.
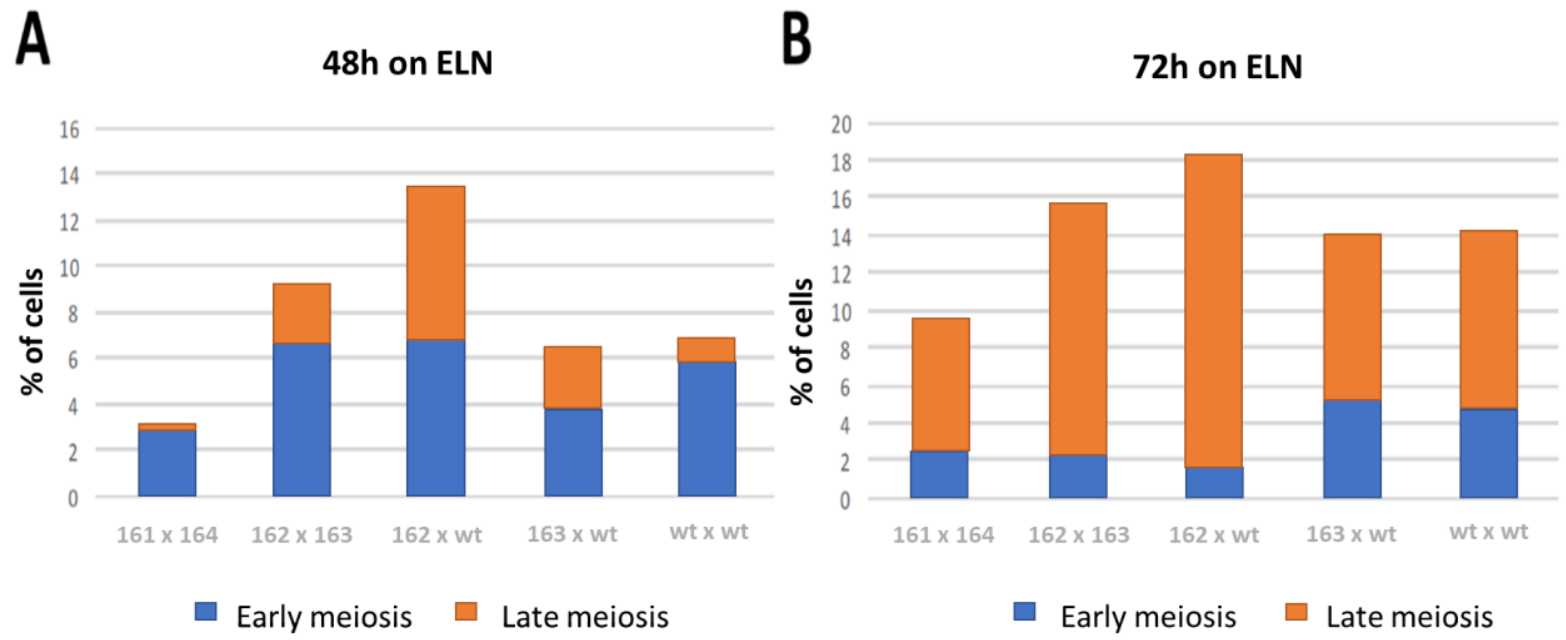

\section{Figure 4.2 Quantification of meiotic events to evaluate Pmeu27D progression through meiosis}

The total number of cells in a population were assessed for mitosis or meiosis based on nuclear and cell morphology. Strains were crossed on ELN, fixed in 70\% ethanol and DNA stained with DAPI (section 3.4)

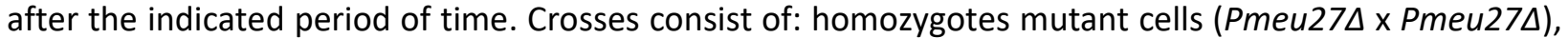

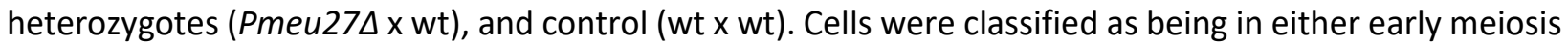
(all meiotic events until anaphase I) or late meiosis (events from anaphase II to sporulation). (A) 48-hours after mating; (B) 72-hours after mating

Sabatinos has shown that $c h k 1^{+}$overexpression significantly increases time in the first anaphase as well as meiotic abnormalities. Therefore, we also quantified the number of chromosome missegregation events on the same 72-hour data set (Fig 4.2) to determine if Pmeu27A causes an increase in abnormalities similar to $c h k 1^{+}$overexpression. Only cells in late meiosis, anaphase II through sporulation, were considered in this analysis. These cells have at least three DAPI-stained masses within each ascus. Abnormal meiotic events are defined as: greater or less than four spores formed in an ascus; greater or less than four nuclei in spores within an ascus; larger amounts of DNA in some spores over others, signifying uneven DNA segregation; or additional DNA within encapsulated spore(s) (see Fig 4.3 for examples). Greater than $5.6 \%$ of the Pmeu27D homozygous population has abnormal meiotic DNA 
segregation. This increased proportion of abnormal meiotic events is significantly different $(p=0.033)$ from

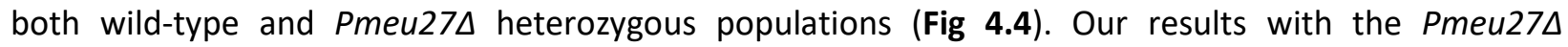
homozygous crosses are similar to $c h k 1^{+}$overexpression during meiosis, with a higher frequency of abnormal meiotic segregation events (Sabatinos \& Forsburg, in prep). In contrast, Pmeu27 2 heterozygotes are comparable to wild-type, suggesting that both alleles of the gene must be removed in order to produce a chk1+ overexpression phenotype.
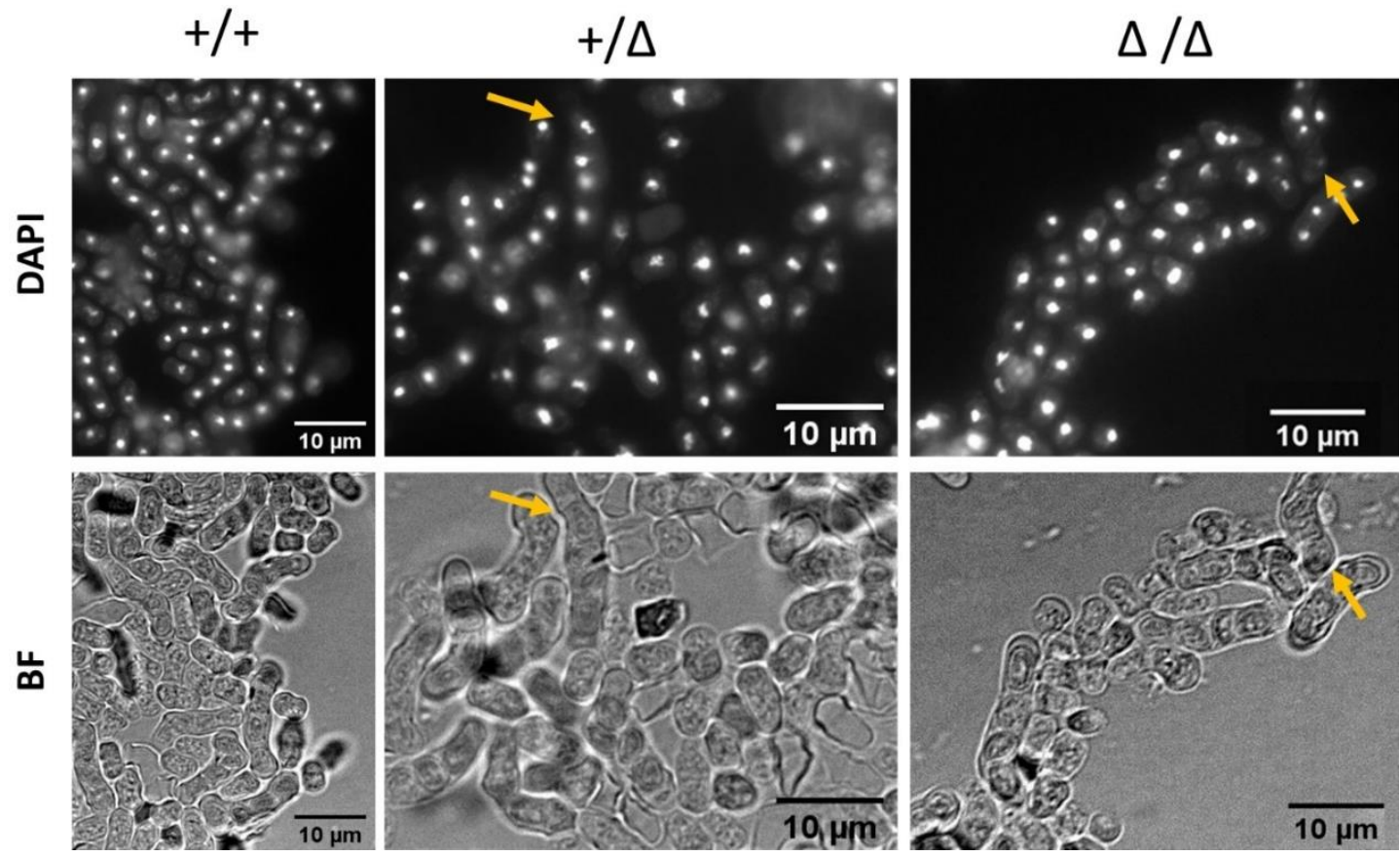

Figure 4.3 Chromosome mis-segregation in Pmeu27 4 following meiosis and sporulation

Images of Pmeu27 2 crosses 72 -hours after mating; fixed in $70 \%$ ethanol and stained with DAPI; viewed at 60X magnification. Crosses classified as: wild-type control $(+/+)$, Pmeu27 $\Delta$ heterozygotes $(+/ \Delta)$, or Pmeu27 $\Delta$ homozygotes $(\Delta / \Delta)$. Examples of abnormal meiotic events considered in Fig 4.4 include fragmented DNA $(+/ \Delta)$ and spores lacking DNA $(\Delta / \Delta)$.

\subsubsection{Effect of nitrogen starvation on Pmeu27A}

In a cycling population, over $70 \%$ of vegetative fission yeast are found in the $\mathrm{G} 2$ phase, having two DNA content (" 2 C" DNA). Nitrogen starvation promotes two rounds of division before cells enter a G0 state with 1C DNA [68]. This is similar to the process of meiotic initiation, but the absence of a mating partner promotes G0 dormancy instead of meiotic conjugation and progression. When nitrogen is replenished, cells re-enter the mitotic growth phase and can again be found in the $2 \mathrm{C}$ state [5].

To determine if the loss of meu $27^{+}$transcription impacts cell cycle transitions caused by nitrogen depletion, we collected samples during nitrogen starvation and release (Fig 4.5 A) then observed DNA 
content by flow cytometry. As previously reported, both wild-type and Chk1-HA strains show 2C DNA content as asynchronous (AS) cultures, then transition to 1C DNA in the absence of nitrogen. Following the addition of nitrogen, cells shift to the right and accumulate $2 \mathrm{C}$ DNA once more at $2 \mathrm{~h}$ and $4 \mathrm{~h}$ postrelease (Fig 4.5 B). The chk1 $\Delta$ cells accumulate in $1 C$ during nitrogen starvation but experience a delayed recovery post-release; both $1 \mathrm{C}$ and $2 \mathrm{C}$ DNA peaks were present at $4 \mathrm{~h}$ post-release (Fig $4.5 \mathrm{~B}$ ). Pmeu27A cells are similar to wild-type and Chk1-HA strains, suggesting failure to transcribe $m e u 27^{+}$does not impact cell cycle transitions during or post-nitrogen starvation (Fig 4.5 B).

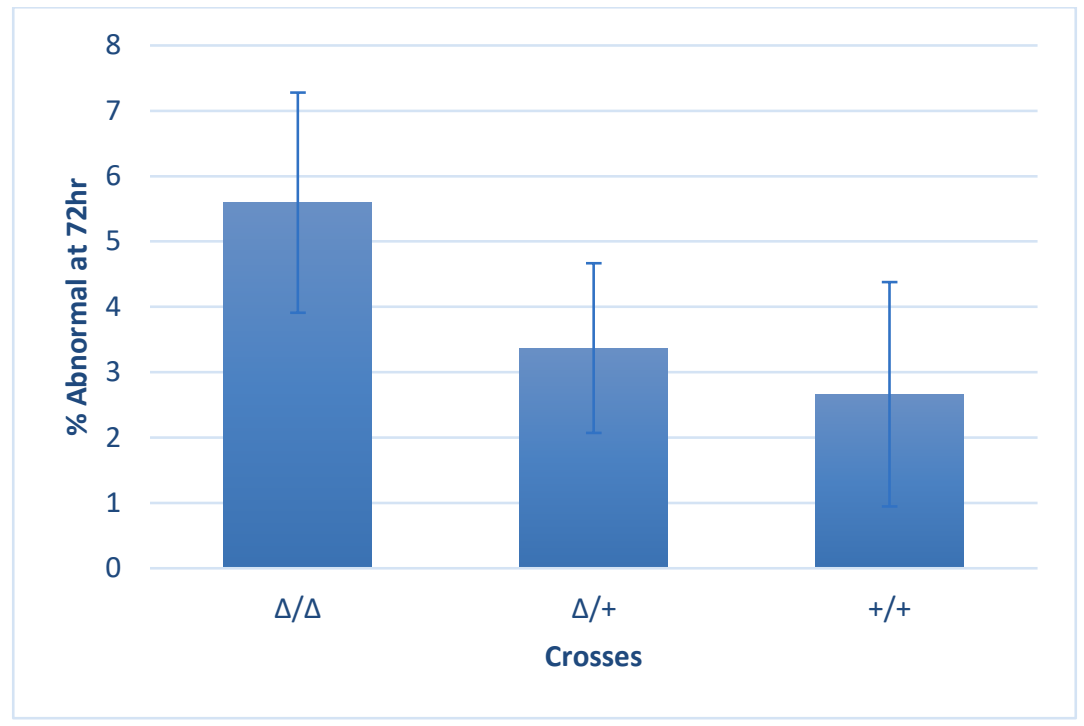

Figure 4.4 Frequency of abnormal meiotic events in Pmeu27 4 crosses

Number of late meiotic abnormalities 72-hours after mating, based on the manual scoring of microscopy images from three independent experiments. Crosses: Pmeu27 $\Delta$ homozygotes $(\Delta / \Delta)$, heterozygotes $(+/ \Delta)$, and wild-type control $(+/+)$. Error bars show a $95 \%$ confidence interval within each population. A chisquared test confirms that the proportion of abnormal meiotic events is increased in the homozygous mutant $\operatorname{cross}(\Delta / \Delta)$ compared to the other groups, $p=0.033$.

Genome-wide studies have revealed nitrogen depletion causes rapid induction of many genes and is associated with local changes in chromatin, in particular, nucleosome and heterochromatin island depletion [61], [69]. To investigate RNA levels of $c h k 1^{+}$and $m e u 27^{+}$, RNA was harvested throughout the nitrogen starvation experiment (sections 3.6 \& 3.8). Using one-step RT-qPCR and the $2^{-\Delta \Delta C T}$ method, chk $1^{+}$ and meu $27^{+}$RNA levels were normalized to act $1^{+}$levels. We compared RNA levels within each strain relative to asynchronous values to evaluate changes within a strain ("AS-normalized"). We also examined

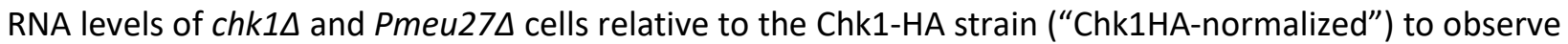
differences relative to the wild-type strain in various conditions of nitrogen block or release. 
A

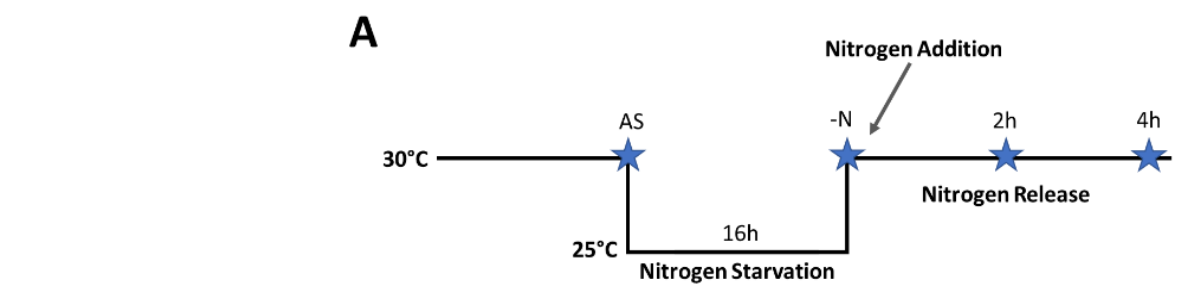

B
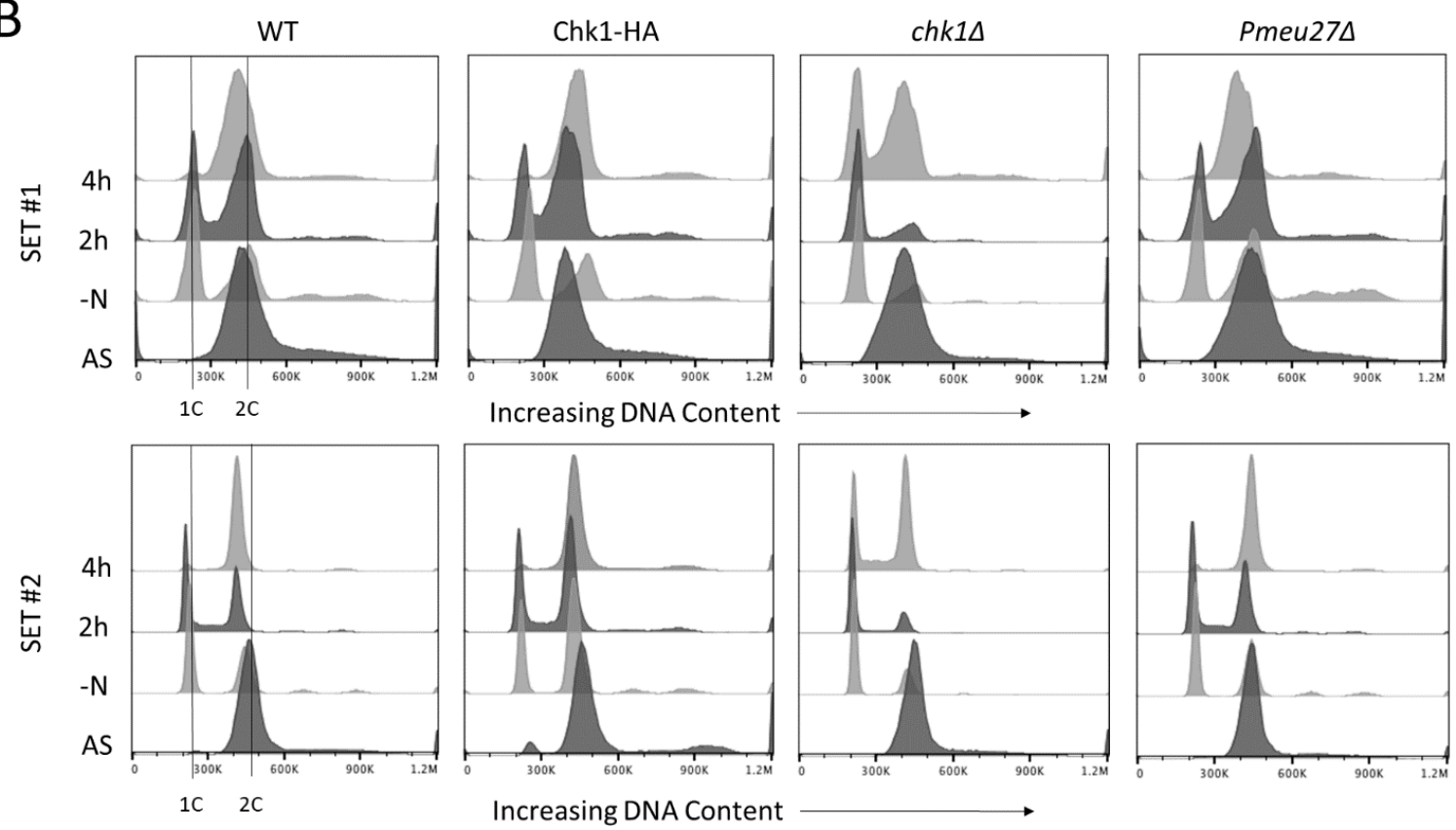

Figure 4.5 Effect of nitrogen starvation on Pmeu27 cell cycle kinetics

(A) Nitrogen starvation experiment schematic. Timepoints: asynchronous (AS) in EMM plus supplements, nitrogen starvation after $16 \mathrm{~h}(-\mathrm{N})$, and two time points $(2 \mathrm{~h} \& 4 \mathrm{~h})$ post-nitrogen restoration. Samples were fixed in $70 \%$ ethanol and stained with SYTOX green to observe total DNA content via flow cytometry (sections 3.6 \& 3.7). (B) Flow cytometry depicting total DNA content of two separate experiments (Set \#1 \& Set \#2). Unreplicated and replicated DNA are denoted as $1 \mathrm{C}$ and $2 \mathrm{C}$, respectively.

The Chk1-HA strain shows an increase in chk1+ levels after nitrogen block, which decrease to baseline levels at $4 \mathrm{~h}$ post-release (Fig 4.6 A). meu $27^{+}$is not induced to the same extent with nitrogen block and release in Chk1-HA cells and decreases to half the asynchronous levels 4h post-release (Fig 4.6 B). Pmeu27A cells have a similar chk1+ pattern as the Chk1-HA, increasing during nitrogen arrest and returning to asynchronous levels post-release (Fig $4.6 \mathrm{~A}$ ). Interestingly, meu27 $7^{+}$RNA appears present in the

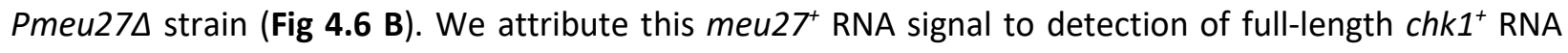
transcripts as a result of primer design. When Pmeu27 RNA levels are compared relative to wild-type Chk1-HA, there is no induction of $m e u 27^{+}$and $c h k 1^{+}$RNA levels are similar before and after nitrogen release (Fig 4.6 C \& D). Since Pmeu27 RNA levels remain consistent between $c h k 1^{+}$and $m e u 27^{+}$when compared to Chk1-HA, it indicates that they are in fact an amplification of the same initial RNA. 
A

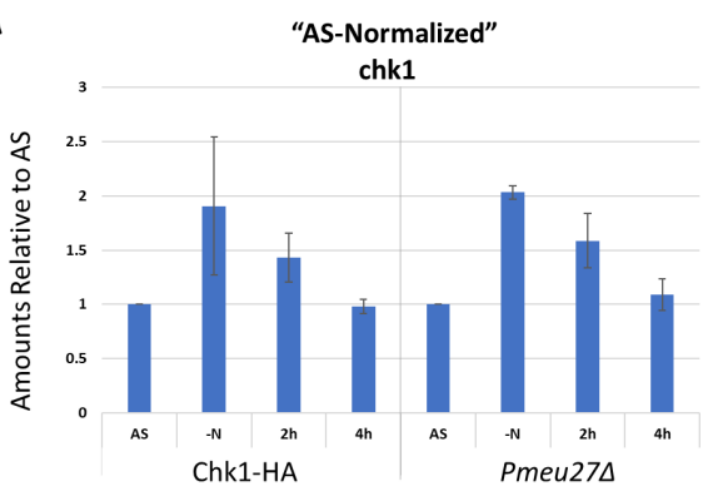

C

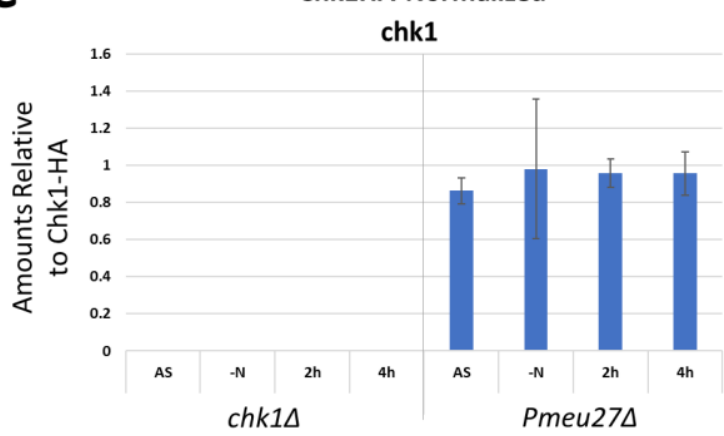

B

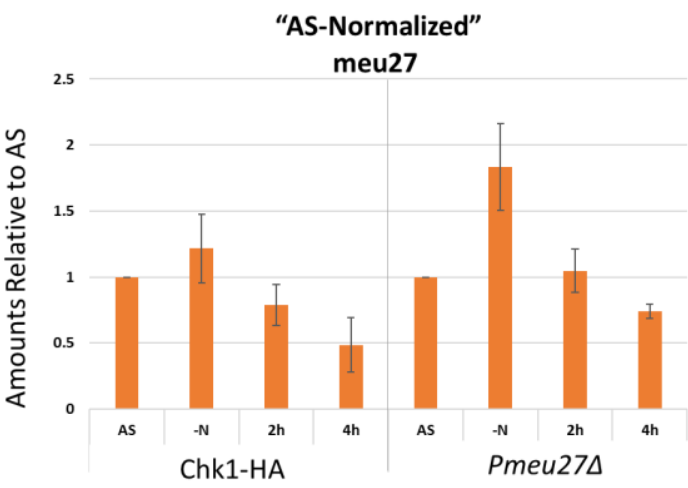

D

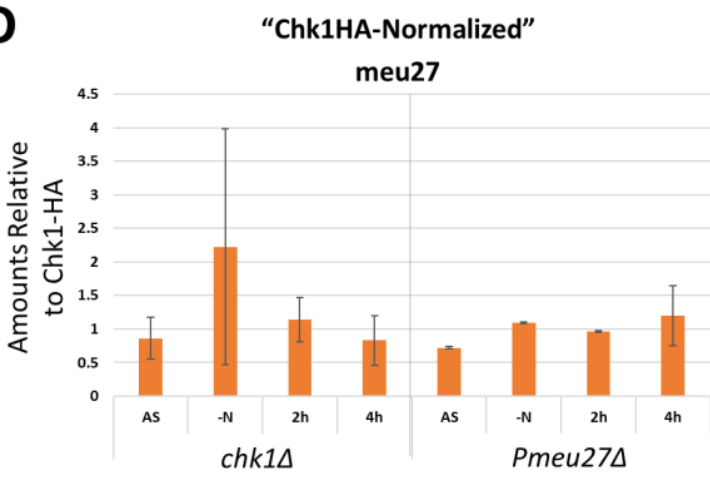

Figure 4.6 chk1 ${ }^{+}$and $m e u 27^{+}$RNA levels in Pmeu27 $\Delta$ cells

Samples taken at the indicated time points throughout the nitrogen starvation experiments (Fig 4.5 A). Relative quantification of $c h k 1^{+}$and meu27 $7^{+}$RNA levels using the $2^{-\Delta \Delta C T}$ method (section 3.8), averaged over two biological replicates from two experiments. (A) chk1+ levels relative to AS timepoint, "ASnormalized"; (B) meu27+ levels relative to AS timepoint, "AS-normalized"; (C) chk1+ levels relative to Chk1HA, "Chk1HA-normalized"; (D) meu27 levels relative to Chk1-HA, "Chk1HA-normalized"

\subsection{Characterization of $m e u 27^{+}$overexpression (OE)}

To determine the effect of meu27+ $7^{+}$overexpression (OE) on nitrogen starvation and release, the meu27+OE strain was grown both in the presence and absence of uracil (ON and OFF states, respectively) and subjected to the same nitrogen starvation experiment (Fig 4.5 A) as Pmeu27D. Samples were collected for flow cytometry of DNA content. I expected the DNA peaks to be $2 \mathrm{C}$ in asynchronous cultures, then $1 \mathrm{C}$ following nitrogen starvation, and gradually returning to $2 \mathrm{C}$ after release and nitrogen feeding. I previously noted that chk1 $\Delta$ cells are different from wild-type and are slow to release from the 1C DNA state. Namely, a strong $1 \mathrm{C}$ is still present at $4 \mathrm{~h}$ post-release. I predicted that meu $27^{+}$overexpression would negatively regulate $c h k 1^{+}$transcription by convergent transcription-interference and that this would phenocopy chk1 $\triangle$ cells. I found that $m e u 27^{+} O E$, in both the ON and OFF states, showed a similarly slowed release from nitrogen arrest as chk1 cells (Fig 4.7). Interestingly, the meu27+ OFF state, which did not 
have uracil in the media, resembled more the chk1 $\Delta$ with a larger $1 C$ peak than the ON state, containing uracil. Since meu27+OE ON cells were grown continuously in the presence of uracil, this suggests a potential negative feedback mechanism to reduce $m e u 27^{+}$copies during long-term induction in haploid cells, as opposed to the short-term induction of the $u r g 1^{+}$promoter in $m e u 27^{+} O E$ OFF by alternate factors.
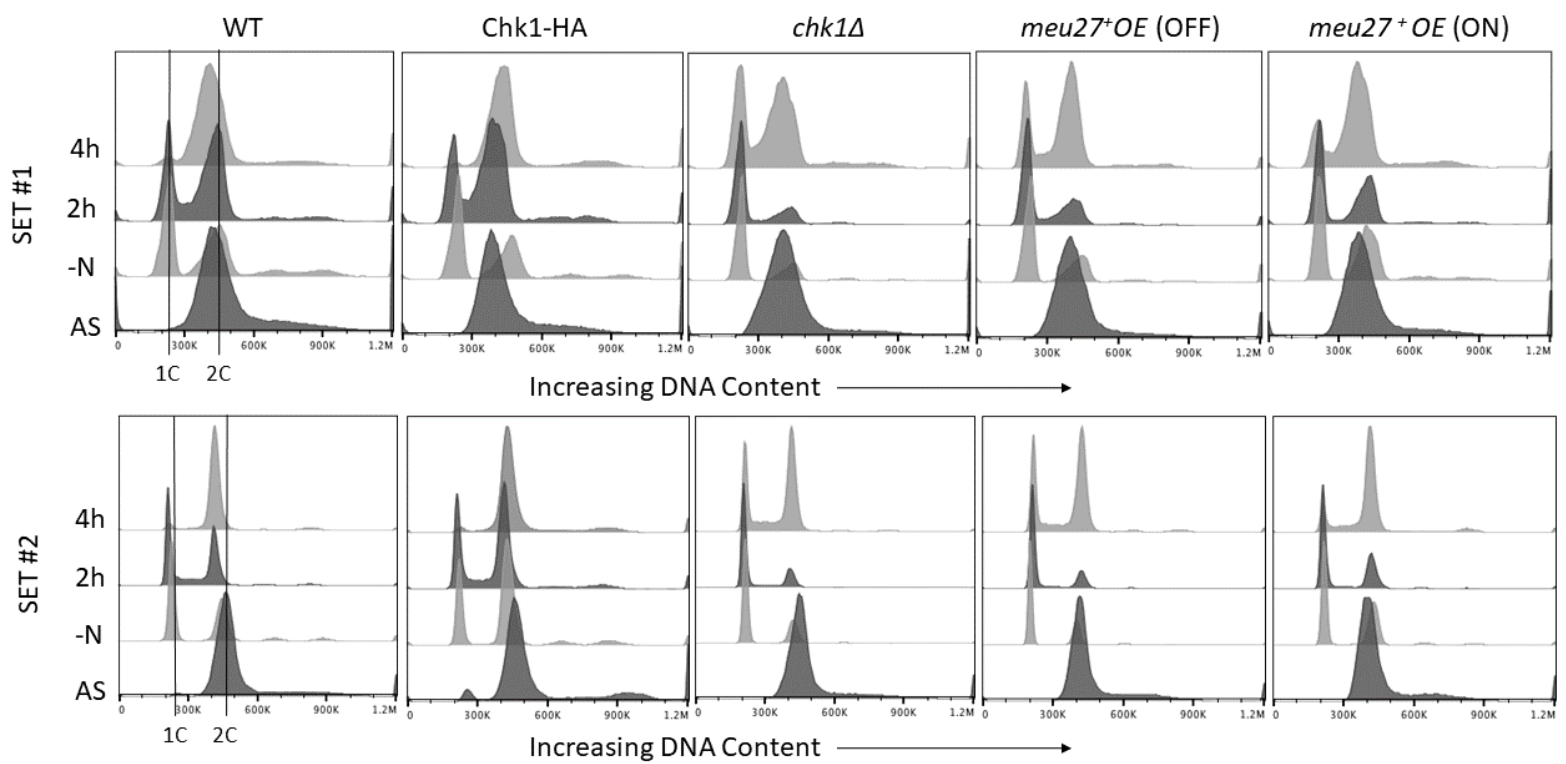

Figure 4.7 Effect of nitrogen starvation on meu27 $O E$ cell cycle kinetics

Total DNA content from the two nitrogen starvation experiments (Set \#1 \& Set \#2; section 3.6). Samples were fixed in $70 \%$ ethanol and stained with SYTOX green for analysis by flow cytometry (section 3.7). Wildtype (WT), Chk1-HA, and chk1 $\triangle$ are the same control samples shown in Fig 4.5 B. The meu2 $7^{+} O E$ strain was grown both in the presence and absence of uracil, resulting in an ON and OFF state, respectively. Unreplicated (1C) and replicated DNA (2C) are indicated in wild-type

We investigated further using RT-qPCR (section 3.8) to test the effect of uracil addition on our meu27+OE strain. The $2^{-\Delta \Delta C T}$ method was used to normalize RNA signal relative to act $1^{+}$RNA levels and then compared within the strain, "AS-normalized", and relative to wild-type Chk1-HA, "Chk1HAnormalized". When compared within strain, meu27+ RNA levels in the wild-type Chk1-HA strain increase under nitrogen starvation and then decrease post-release (Fig 4.8 B). This trend of increasing in the absence of nitrogen and decreasing with the addition of nitrogen is conserved for meu27 RNA in both meu $27^{+} O E$ OFF and ON states, although levels increased 8-fold in the ON state during nitrogen starvation. meu $27^{+} O E$ OFF displays a steady decrease in meu2 $7^{+}$levels over the $2 \mathrm{~h}$ and $4 \mathrm{~h}$ post-release, returning to baseline asynchronous levels. On the other hand, meu27+ RNA in meu27+OE ON exhibit a much more drastic, 3-fold decrease by the $2 \mathrm{~h}$ post-release time point, which corresponds to an increase in chk $1^{+}$levels (Fig 4.8 A \& B). In addition, the peak of meu $27^{+}$during nitrogen starvation and increased levels at 4 h postrelease in $m e u 27^{+} O E O N$ correlates to a decrease in $c h k 1^{+}$levels at both of these time points. 

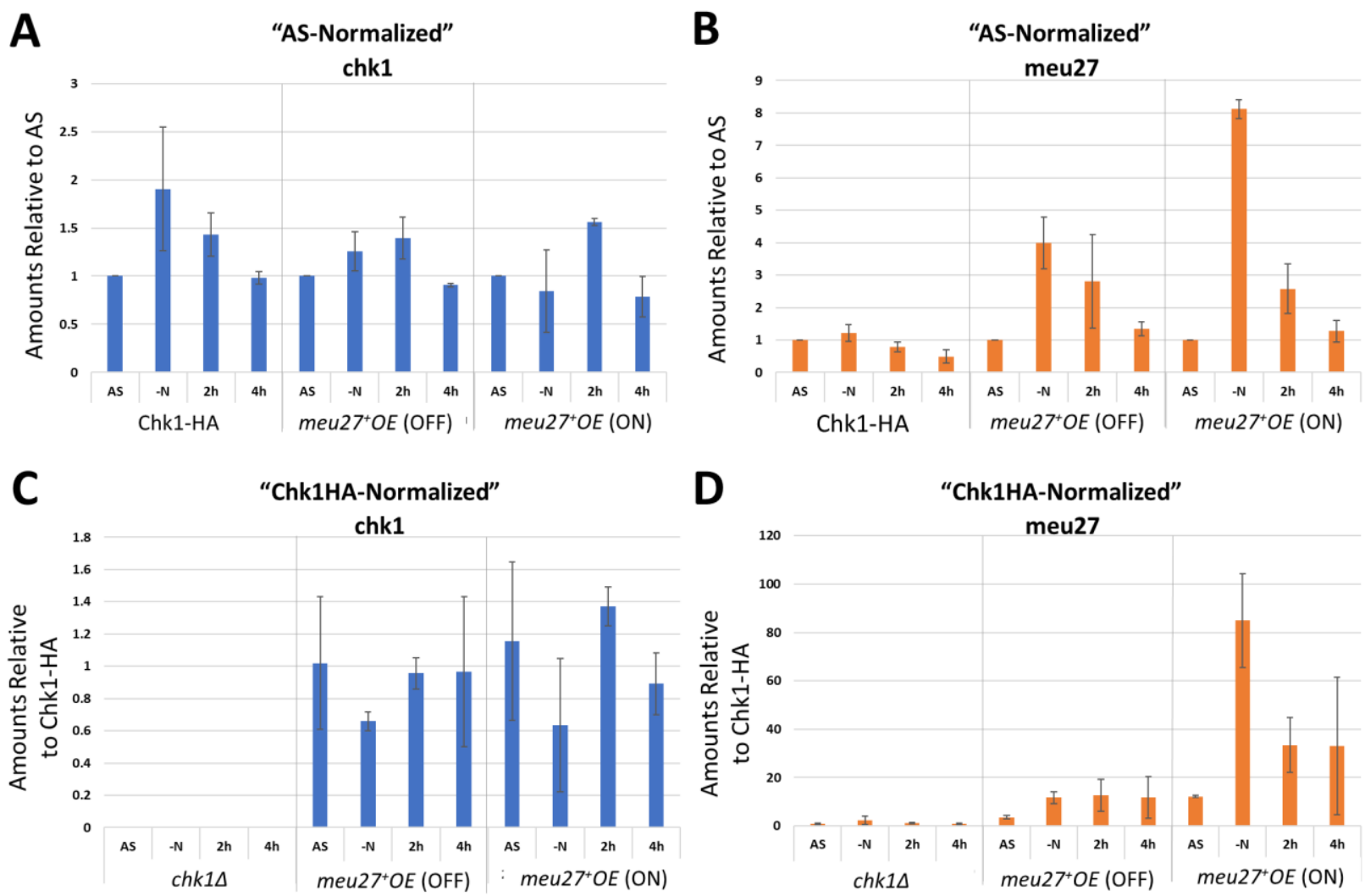

Figure 4.8 chk1 ${ }^{+}$and $m e u 27^{+}$RNA levels in $m e u 27^{+} O E$ cells

meu27+OE was grown in the presence and absence of uracil (ON and OFF states, respectively). Samples taken at the indicated time points throughout nitrogen starvation and recovery (Fig $4.5 \mathrm{~A}$ ). Relative quantification of $c h k 1^{+}$and meu27+ RNA levels using the $2^{-\Delta \Delta C T}$ method (section 3.8) were averaged over two biological replicates from two experiments. (A) chk1+ levels relative to AS timepoint, "AS-normalized"; (B) meu27 levels relative to AS timepoint, "AS-normalized"; (C) chk1+ levels relative to Chk1-HA, "Chk1HAnormalized"; (D) meu27+ levels relative to Chk1-HA, "Chk1HA-normalized"

chk1 ${ }^{+}$RNA levels in Chk1-HA cells peak during nitrogen starvation with an almost two-fold increase, then decrease to asynchronous levels by $4 \mathrm{~h}$ during release (Fig $4.8 \mathrm{~A}$ ). However, when chk1+ levels in the meu27+OE are compared to the Chk1-HA strain, a similar trend is observed between the ON and OFF states, namely, a decrease during nitrogen starvation (Fig 4.8 C). This effect corresponds to the large increase in meu27 $7^{+}$RNA: 12-fold higher in OFF, and 80-fold higher in the ON state (Fig 4.8 D). As expected, the increase in meu27 $7^{+}$is more pronounced in meu27+OE ON during nitrogen starvation. Together, results suggest that increased meu27 $7^{+}$expression negatively impacts chk1 $1^{+}$RNA levels.

\subsection{Effect of a $c h k 1^{+}>>\operatorname{KanMX6}$ ( $>\left\langle<m e u 27^{+}\right.$broken transcriptional unit}

Previous studies have shown that insertion of a reporter gene between a convergent gene pair leads to altered expression of the now tandem gene(s) [21], [28]. To test whether our convergent gene 
pair responded similarly, a KanMX6 reporter gene was inserted after the $c h k 1^{+}$coding sequence. This new strain, chk1+>>KanMX6 $>><<m e u 27^{+}$, puts $c h k 1^{+}$and KanMX6 in a tandem orientation, and KanMX6 and meu27 $7^{+}$in a convergent orientation (Fig B3, Appendix B). This strain, named $c h k 1^{+} /$meu $27^{+}$, was tested with nitrogen starvation and release to compare with Pmeu27 27 and $m e u 27^{+} O E$ in flow cytometry of DNA content and RT-qPCR. With no transcriptional interference in the absence of meu27 $7^{+}$expression, chk $1^{+}$ expression is expected to increase. Chk1 overexpression causes cell elongation and arrest in G2, which can be detected by DNA content and cell length in flow cytometry. I expected that $\mathrm{chk} 1^{+} / \mathrm{meu} 27^{+}$would display a DNA content phenotype similar to wild-type. I found that the DNA content of $c h k 1^{+} / m e u 27^{+}$cells in nitrogen block and release is similar to wild-type (Fig 4.9). This suggests that this transcriptional unit does not impact mitotic cell cycle during nitrogen stress or recovery.
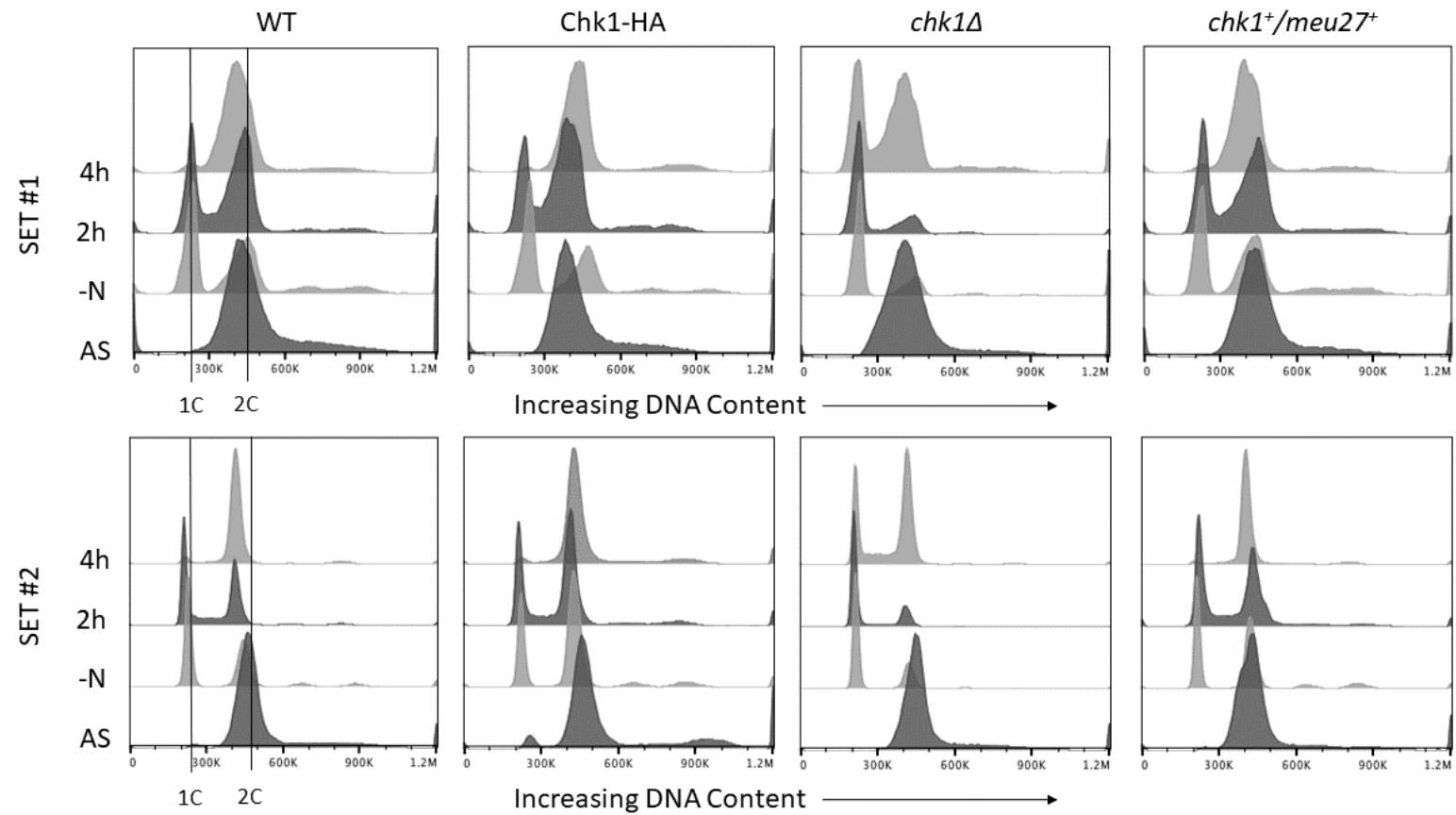

Figure 4.9 Effect of nitrogen starvation on $c h k 1^{+} / \mathrm{meu}^{2} 7^{+}$cell cycle kinetics

Total DNA content during nitrogen starvation, in duplicate (Set \#1 \& Set \#2). Samples were obtained at indicated time points, fixed in $70 \%$ ethanol, and stained with SYTOX green for analysis by flow cytometry (section 3.7). Wild-type (WT), Chk1-HA, and chk1 $\Delta$ are the same control samples shown in Fig 4.5 A \& 4.7. Unreplicated and replicated DNA are indicated in wild-type at $1 \mathrm{C}$ and $2 \mathrm{C}$ markers, respectively.

Despite no apparent disruption to cell cycle progression under stress, there may be changes in the transcription. Comparing $c h k 1^{+}$and $m e u 27^{+}$RNA levels to the asynchronous population within a strain shows how each strain responds during nitrogen starvation. In wild-type cells, there is a 3-fold increase of both $c h k 1^{+}$and meu27+ RNA levels under nitrogen starvation, followed by a significant decrease $2 \mathrm{~h}$ postrelease, with levels comparable to asynchronous after 4 h (Fig $4.10 \mathrm{~A} \& \mathrm{~B}$ ). The $c h k 1^{+} / \mathrm{meu} 27^{+}$cells have 
an increase in $c h k 1^{+}$and meu $27^{+}$transcription during nitrogen starvation, but to a lesser degree than within the wild-type strain. During release, $c h k 1^{+}$and meu $27^{+}$RNA decreases more slowly than wild-type

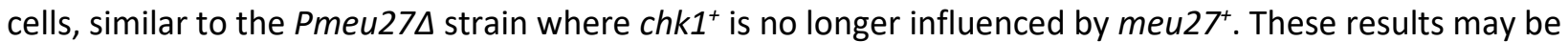
explained in more depth with the comparison of RNA levels at each time point to those of wild-type. chk1+ RNA levels are approximately $60 \%$ of wild-type during nitrogen starvation but become higher than wildtype during release (Fig $4.10 \mathrm{C}$ ). Similarly, meu27 $7^{+}$levels decrease in the $c h k 1^{+} / \mathrm{meu} 27^{+}$strain under nitrogen starvation, then increase nearly 2.5 -fold at 4 h post-release (Fig $4.10 \mathrm{D}$ ). In the $\mathrm{chk} 1^{+} / \mathrm{meu} 27^{+}$ strain, meu27+ remains in a convergent orientation with the reporter gene $K a n M X 6$, therefore a decrease in RNA levels is consistent with an increase in KanMX6. The reason for chk1+ RNA decreasing during nitrogen starvation followed by a steady increase is not understood. However, this altered pattern from wild-type suggests that there is a loss of $c h k 1^{+}$and $m e u 27^{+}$dynamics, enabling alternative and/or independent modes of regulation in $\mathrm{chk} 1^{+} / \mathrm{meu} 27^{+}$.

A

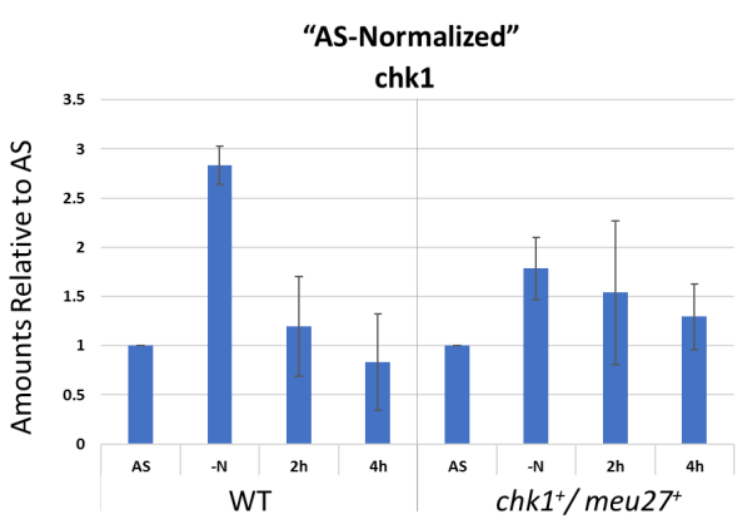

C

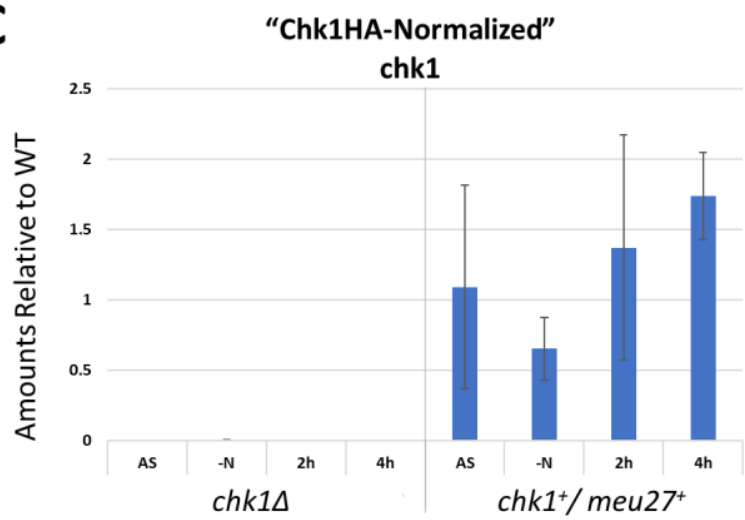

B

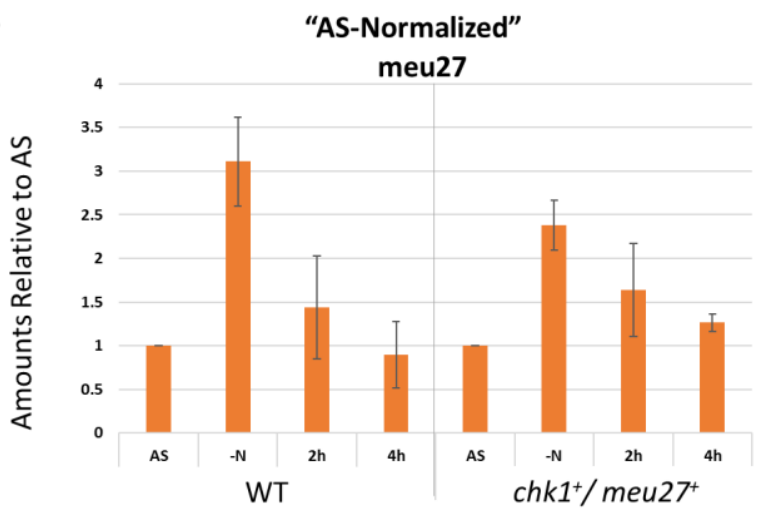

D

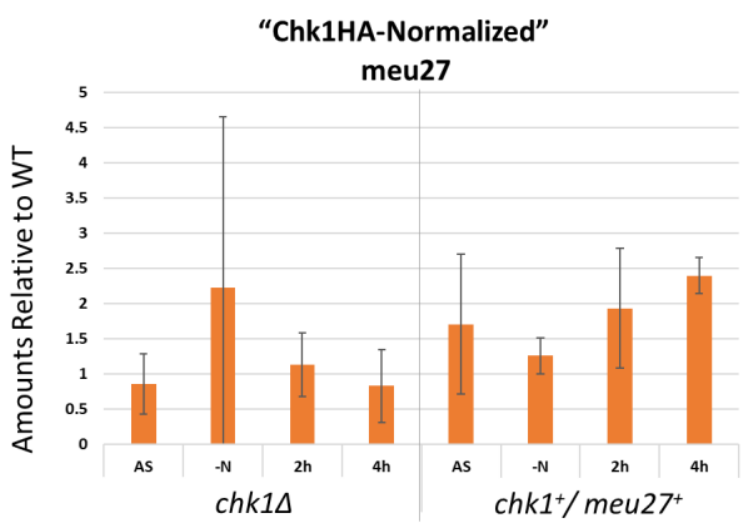

Figure 4.10 chk1 ${ }^{+}$and $m e u 27^{+}$RNA levels in chk1+/meu2 $7^{+}$cells

Samples taken at respective time points during nitrogen starvation and recovery (Fig $4.5 \mathrm{~A}$ ). Relative quantification of $c h k 1^{+}$and meu27+ RNA levels using the $2^{-\Delta \Delta C T}$ method (section 3.8) were averaged over two biological replicates from two experiments. (A) chk1+ levels relative to AS timepoint, "AS-normalized"; (B) meu $27^{+}$levels relative to AS timepoint, "AS-normalized"; (C) chk1+ levels relative to Chk1-HA, "Chk1HAnormalized"; (D) meu27 $7^{+}$levels relative to Chk1-HA, "Chk1HA-normalized" 


\section{Chapter 5:}

\section{Discussion}

Strict regulation of cell cycle checkpoint mechanisms maintains genetic integrity throughout cellular division. The two major pathways in eukaryotes that control cell cycle are the DNA replication and the DNA damage checkpoints. Many of the DNA damage checkpoint proteins form convergent gene pairs, including Rad3, Rad26, Crb2, Chk1, and Cdc2; the convergent gene for each of these is potentially stressinducible. Previous studies have confirmed that convergent gene orientations lead to transcriptional gene silencing in both cis and trans mechanisms, by physical collision of the RNA polymerase II and the formation of dsRNA, respectively [15], [20], [21], [28]. dsRNA from convergent genes has been shown to induce RNAi in S. pombe, Drosophila , and mammalian cells [21], [22]. These results demonstrate that convergent transcription contributes to transcriptional interference leading to gene silencing. However, transcriptional gene silencing has not been shown in checkpoint modulation of S. pombe, despite the significant number of convergent checkpoint genes. In this study, we investigated the effect of transcription-interference mechanisms on DNA damage checkpoint in fission yeast. We propose that the convergent orientation of $c h k 1^{+}$and $m e u 27^{+}$regulates $c h k 1^{+}$transcription and therefore, has the potential to suppress checkpoint under environmental stress.

\subsection{Evidence for convergent transcriptional effects on $\operatorname{chk} 1^{+}$expression}

Convergent genes have been shown to cause gene silencing through transcriptional interference mechanisms in S. pombe [21], [28]. We hypothesize that the convergent transcription of $c h k 1^{+}$and $m e u 27^{+}$ acts as a regulatory mechanism capable of suppressing checkpoint. During the vegetative cell cycle, the Chk1 protein is activated to prevent cellular division in the presence of DNA damage. Meu27 is present at very low levels in vegetative cells as it is a meiotically upregulated protein. Yet meiosis is a linear differentiation pathway that favours the generation of DNA damage which is essential for homologous recombination and proper meiotic segregation. Supporting this, cells that do not form meiotic DNA double strand breaks (rec12 $\triangle$ mutant in S. pombe; SPO11 $\triangle$ in other eukaryotes) have very low spore viability [70], [71]. Mice that lack SPO11 show impaired fertility caused by diminished DSB formation [72]. Therefore, formation and retention of DSBs until the end of meiosis is important to fertility [73]. In support of this concept, chk1+ RNA levels decrease in early meiosis. Further, Chk1 phosphorylation does not occur during early meiosis, despite the deliberate DNA damage induced at this stage [13], [74]. We hypothesize that 


\section{DISCUSSION}

chk1 $1^{+}$levels will increase when the meu $27^{+}$promoter is inactive and $c h k 1^{+}$levels will decrease when meu $27^{+}$is overexpressed. This modulation will occur in meiosis and impact meiotic chromosome stability. In addition, both $c h k 1^{+}$and $m e u 27^{+}$levels are expected to increase in meiosis due to a loss of regulation when the convergent gene pair is disrupted.

In the promoter deletion strain, Pmeu27A, chk1+ RNA levels display a similar trend to wild-type when compared to the asynchronous cultures (Fig 4.6 A) and remain constant near 1 when compared to Chk1-HA (Fig $4.6 \mathrm{C}$ ). This suggests that $m e u 27^{+}$transcription does not directly impact chk1 $1^{+}$levels. However, meu $27^{+}$RNA appears to be present, yet levels mimic those of $c h k 1^{+}$RNA when normalized to either asynchronous (Fig 4.6 B) or wild-type (Fig 4.6 D) cells. We speculate that the primers used for meu $27^{+}$detection are in fact amplifying the corresponding region of $c h k 1^{+}$transcripts. The reverse of this was observed when downstream primers were used to amplify the region between $c h k 1^{+}$exons 6-7 as meu $27^{+}$RNA levels appeared significantly higher (data not shown). In addition, meu27 $7^{+}$transcript levels in AS-normalized cells appear to double in Pmeu27A under nitrogen starvation, even though wild-type Chk1-HA has only a slight increase of approximately 25\% (Fig 4.6 B). This increase is believed to be the result of more full-length chk1 $1^{+}$transcript in the absence of $m e u 27^{+}$, which overlaps with the meu27+ amplicon. In the Chk1-HA strain, increased levels of meu27 $7^{+}$RNA would prevent full length transcripts, allowing for a more accurate representation of meu $27^{+}$levels. The amount of $c h k 1^{+}$seemingly remains the same between wild-type Chk1-HA and Pmeu27D in the absence of nitrogen (Fig 4.6 A) as the rate of chk $1^{+}$transcription does not appear to be affected, only the length of transcript. In human cells, a Chk1 splice variant lacking exon 3 has been identified which interacts with full-length Chk1 to promote the G2 to $\mathrm{M}$ transition [75]. We speculate that Chk1 splice variants may also be found in S. pombe, but this has not been confirmed. Chk1 splice variants could impact the detection of $c h k 1^{+}$RNA depending on the primers used. Further investigation is required in Pmeu27 $\Delta$ to determine the absolute levels of meu27 ${ }^{+}$ and $c h k 1^{+}$RNA transcripts. Strand-specific reverse transcription steps, with the use of strand-specific primers, could also be used to determine discordant $c h k 1^{+}$and $m e u 27^{+}$results.

We have demonstrated a relationship between $c h k 1^{+}$and meu $27^{+} \mathrm{RNA}$ expression levels that is lost when the convergent system is disrupted. When meu27+ is overexpressed in the absence of nitrogen, an increase of over 80-fold is observed compared to wild-type Chk1-HA (Fig. 4.8 D). Decreased chk1 ${ }^{+}$RNA at the corresponding time point (Fig $4.8 \mathrm{C}$ ) is believed to result from the significantly increased $m e u 27^{+}$

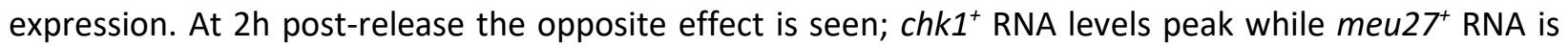
dramatically decreased (Fig 4.8). The opposing response between the RNAs under varying environmental 


\section{DISCUSSION}

conditions suggests that convergent transcription regulates absolute amounts of each transcript. While $c h k 1^{+}$transcript is not entirely depleted, other regulatory mechanisms may influence Chk1 levels including translation, protein folding and checkpoint activation. Further investigation into changes in Chk1 protein levels and phosphorylation is required.

In contrast to the relationship observed under meu2 $7^{+}$overexpression, loss of convergence imparts independent regulation in the $c h k 1^{+} /$meu $27^{+}$strain. Wild-type cells show increased $c h k 1^{+}$and meu $27^{+}$levels following nitrogen arrest, returning to asynchronous levels during release (with nitrogen refeeding). This pattern is lost when convergence is broken. When compared within the strain, both chk1+ and meu $27^{+}$RNA levels increase by $250-300 \%$ during nitrogen starvation and remain increased compared to asynchronous cultures at $4 \mathrm{~h}$ post-release (Fig 4.10 A \& B). Previous studies demonstrated similar elevated transcript levels in RNAi genes that directly result from changing convergent genes to a tandem orientation [21], [28]. However, when compared to wild-type, chk1 $1^{+} / \operatorname{meu} 27^{+}$RNA levels appear to decrease during nitrogen starvation (Fig. 4.10 C \& D). With the reporter gene, KanMX6, maintaining a convergent orientation with meu27, a decrease in RNA levels can result from increased transcription of KanMX6, consistent with active transcriptional interference mechanisms. The apparent decrease in chk1 ${ }^{+}$ RNA levels are believed to result from a combined increase in chk1+ expression and RNAi activity, which would lead to increased degradation of $c h k 1^{+}$RNA. An increase in $c h k 1^{+}$RNA degradation would result in lower levels of detection, consistent with a decrease in RNA levels compared to wild-type. Together, our results provide evidence for a loss of convergent transcriptional effects between meu27+ and chk1 $1^{+}$with a forced tandem orientation by the insertion of the reporter gene between the coding sequences.

\subsection{Potential for checkpoint regulation by convergent transcription}

Sabatinos' previous research has shown that chk1+ overexpression causes chromosome missegregation during meiosis (Sabatinos \& Forsburg, in prep). We predict that this phenotype would be mimicked in Pmeu27A cells due to the loss of convergent transcriptional interference. We show that homozygous crosses of Pmeu27A have an increased frequency of abnormal meiotic events as a result of chromosome mis-segregation, when compared to both homozygous wild-type and heterozygous

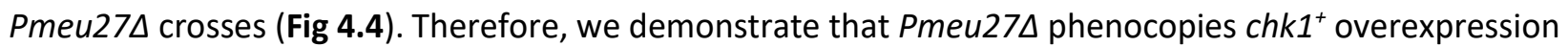
through increased or prolonged checkpoint activation as a direct consequence of meu27+ inactivation.

In addition to higher abnormalities in homozygous Pmeu27 cells, our results show a delay in early meiosis 48 hours after mating in one of the Pmeu27 homozygous crosses, 161x164 (Fig 4.2 A). This 


\section{DISCUSSION}

indicates that there may be a slight delay for meiotic entry, or a delay in meiotic progression. A mitotic lag in the divisions prior to entry into meiosis is consistent with previous research that observed slower cell-cycle progression when chk1+ is overexpressed [49], [67]. Slower mitotic division would result in delayed meiotic entry, which would present as a delay in early meiosis. Another possibility is that there is a meiotic lag as a result of Chk1 activity in early meiosis, causing a delay in meiotic progression. These results were not reflected in the second Pmeu27 homozygous cross, $162 \times 163$, which may be a result of epigenetic differences among strains. Alternatively, strain 162 is an independently isolated version of Pmeu27D that presents a different phenotype in all its crosses and may harbour uncharacterized differences from the other isolates (Fig 4.2). To determine whether these differences are epigenetic or strain-related, we first need to examine the outcome of the alternative Pmeu27 $\triangle$ homozygous mutant

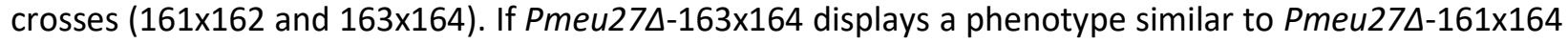

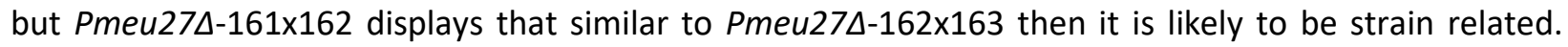
Nonetheless, these results provide evidence that checkpoint regulation is altered in Pmeu27 $\triangle$ cells due to the loss of convergent transcription.

Another method to determine if checkpoint regulation is affected in Pmeu27A is through cell cycle kinetics assessed using flow cytometry. Pmeu27 cells behave like wild-type throughout nitrogen block and release. Wild-type and Chk1-HA cells accumulate with a 1C DNA content during nitrogen starvation as they enter a dormant $\mathrm{G} 0$ state after two rounds of division [5], [68]. We confirm by flow cytometry that wild-type cells with an active Chk1 protein begin to transition back into $\mathrm{G} 2 \mathrm{2h}$ post-release, as demonstrated with an increasing 2C DNA content (Fig 4.5 B). At 4h post-release, cells return to G2, resembling the asynchronous population. Pmeu27 $\Delta$ cells follow this same patter of shifting from a $2 \mathrm{C}$ to a $1 C$ DNA content during nitrogen depletion and returning back to $2 \mathrm{C}$ post-release. These results suggest that checkpoint is not affected during transition back to the mitotic cell cycle from the G0 state with the loss of meu $27^{+}$transcription. In contrast, chk1 $1 \Delta$ mutants remain in $1 \mathrm{C}$ for at least $2 \mathrm{~h}$ following nitrogen renewal (Fig 4.5 B). 4h post-nitrogen addition, cells resume replication and begin to accumulate in G2. This delay suggests that $c h k 1^{+}$has a potential role in transitioning from the $\mathrm{G} 0$ state to the mitotic cell cycle during nitrogen block and release.

When meu $27^{+}$is overexpressed, we predicted that it would behave like a chk1 1 due to convergent transcriptional effects that decrease $c h k 1^{+}$RNA. Indeed, meu $27^{+} O E$ cultures exhibit a delay similar to chk1 $\Delta$ mutants in resuming DNA replication post-nitrogen stress (Fig 4.7). This was true for meu27 $O E$ cells that were grown in the presence (ON) and absence (OFF) of uracil. It has been shown that 


\section{DISCUSSION}

endogenous S. pombe $u \mathrm{rg}^{+}$is induced in response to nitrogen starvation due to nucleosome loss [69]. While a dramatic effect on cell cycle progression was not expected in meu27+OE OFF, $\operatorname{urg} 1^{+}$activation by alternative mechanisms is consistent with the significant increase in $m e u 27^{+}$levels in the OFF state (Fig 4.8). These results suggest that convergent transcription has the potential for checkpoint regulation under environmental stress.

\subsection{The impact of environmental stress on checkpoint regulation}

Environmental stress causes a transcriptional response in cells, upregulating expression of core environmental stress response (CESR) genes under a variety of conditions, such as temperature stress, oxidative stress, osmotic stress and DNA damage [76]. Expression of the majority of these CESR genes is dependent on Sty1, a mitogen-activated protein kinase (MAPK), that stimulates transcription of stressdependent pathways via the transcription factor Aft1 [69], [77]. Additionally, nitrogen starvation causes a rapid induction of many genes, including CESR and Sty1/Aft1-dependent genes [69], although global induction is greatly reduced with sustained stress. We hypothesized that meu27 $7^{+}$RNA levels would increase in the absence of nitrogen as it is a meiotically upregulated protein. In wild-type, there was a $300 \%$ increase in meu $27^{+}$levels following nitrogen arrest, which returned to asynchronous levels at $4 \mathrm{~h}$ post-release (Fig B4 B). In Chk1-HA however, there was less of an effect on meu27 ${ }^{+}$RNA levels, with an increase of only $125 \%$ in nitrogen arrest, which decreased to $50 \%$ of asynchronous levels by 4 h postrelease. This suggests an important discrepancy between the two parent strains used in this study. Although, a similar trend is observed, absolute levels of $c h k 1^{+}$and $m e u 27^{+}$are different. When normalizing RT-qPCR data using the $2^{-\Delta \Delta C T}$ method, Pmeu27 2 and meu27 $O E$ strains were normalized to Chk1-HA whereas $c h k 1^{+} /$meu $27^{+}$was normalized to wild-type, as these were the parent strains used in strain construction, respectively. This allows for greater accuracy when using a relative quantification method.

When $m e u 27^{+}$is overexpressed, meu $27^{+}$RNA levels increase over 80 -fold following nitrogen starvation (Fig $4.8 \mathrm{D}$ ). This significant augmentation in $m e u 27^{+}$transcription is greater than in any other strain, including meu27+OE OFF, where meu27 $7^{+}$RNA levels double relative to Chk1-HA upon nitrogen depletion. In AS-normalized cells, meu27+OE ON is 8-fold higher in the absence of nitrogen (Fig 4.8 B), which mimics levels of meu $27^{+}$RNA during meiosis [74]. It is only when meu27 RNA levels in meu27+OE ON reach those comparable to meiotic levels that a negative impact on chk1+ RNA is observed (Fig 4.8 A). All other strains, including wild-type and Chk1-HA, have increased chk1+ RNA levels in response to nitrogen starvation (Fig 4.6 A, 4.8 A, and 4.10 A). However, in meu27+OE OFF there is a delay in the rise of $c h k 1^{+}$ 


\section{DISCUSSION}

RNA relative to asynchronous, peaking $2 \mathrm{~h}$ post-release instead of in the absence of nitrogen (Fig 4.8 A). Interestingly, this seemingly slower chk1 $1^{+}$RNA increase following nitrogen starvation corresponds to lower chk1+ levels relative to Chk1-HA cells (Fig 4.8 C). Together, these results demonstrate that increased meu $27^{+}$RNA levels negatively impact chk1+RNA under environmental stress. This suggests that meiotically upregulated genes, such as meu $27^{+}$, may be influenced by mitotic stress when no sexual partners are present. 


\section{Chapter 6:}

\section{Conclusions and Future Directions}

A summary of the major findings of this study along with approaches to further expand our knowledge in this growing field of transcriptional regulation of checkpoint induction and maintenance.

\subsection{Conclusions}

This study demonstrates that altered transcription of meu $27^{+}$directly impacts chk $1^{+}$RNA levels. Pmeu27A cells phenocopy chk1+ overexpression with increased abnormal chromosome segregation and slowed progression through meiosis. Similarly, meu $27^{+}$overexpression decreases $c h k 1^{+}$expression; this slows re-entry into the mitotic cell cycle following nitrogen arrest, similar to chk1 $\Delta$ cells. We also provide evidence of a relationship that is lost with the disruption of convergent transcription between $c h k 1^{+}$and meu27 $7^{+}$Collectively, our research shows that a convergent transcription-interference mechanism(s) impacts $c h k 1^{+}$with the potential to regulate checkpoint activity under environmental stress. In addition, our work suggests that mitotic stressors may influence expression of meiotic genes resulting in changes in the transcriptome that affect checkpoint regulation.

\subsection{Future Directions}

Our results suggest additional research areas that must be considered to verify select findings and further characterize the transcription-interference mechanism acting on convergent checkpoint genes.

Spore visualization with psy1-GFP: The $p s y 1^{+}$gene is a syntaxin 1 homologue that localizes at the plasma membrane during vegetative growth, then at the forespore membrane after the first meiotic division [78]. By constructing an S. pombe strain with a green fluorescent protein (GFP) tagged Psy1, the Nakamura Lab was able to capture fluorescent images of live fission yeast during vegetative growth and sporulation [79]. This allows for better visualization of spore walls and would improve our analysis by confirming sporulation more easily and clearly. It would help us to highlight abnormalities that may be subtle and otherwise overlooked.

Western blot for protein levels of Chk1-HA and FLAG-Meu27: Quantification of RNA levels alone is not sufficient to determine whether a gene has been silenced. Corresponding protein levels are required to 
conclude if the transcriptional interference has an effect on protein production and/or activation in the case of checkpoint regulation. Therefore, western blots to detect Chk1-HA and FLAG-Meu27 levels under these environmental conditions is needed to confirm the impact of convergent transcription on checkpoint regulation.

Absolute levels of $c h k 1^{+}$and $m e u 27^{+}$RNA: In this study, a relative analysis was used to highlight the changes in $c h k 1^{+}$and meu $27^{+}$RNA levels under different conditions (AS, $-\mathrm{N}, 2 \mathrm{~h}$, and $4 \mathrm{~h}$ post-nitrogen addition) and between strains. Absolute RNA levels would provide insight into baseline level as well as any potential thresholds or external feedback mechanisms regulating transcription. This analysis is conducted by generating a calibration curve of known amounts of each RNA for comparison in extracted RNA samples.

Strand-specific RT-qPCR: In Pmeu27D, the detected meu27 $7^{+}$RNA amplicon is believed to be an amplification of the corresponding region of $c h k 1^{+}$RNA due to transcript overlap. The amount of meu27 RNA is almost identical to that of $c h k 1^{+}$in each condition when compared to asynchronous cells. Both chk1 $1^{+}$and $m e u 27^{+}$RNA levels remain the same relative to Chk1-HA samples. Amplification of both meu27 and $c h k 1^{+}$transcripts occurred when we used an amplicon of exons 6-7 in chk1 $1^{+}$, which overlaps with the $3^{\prime}$ UTR of meu $27^{+}$(data not shown). For these reasons, strand-specific primers would portray a more accurate representation of meu27 $7^{+}$RNA levels in this strain and others.

Impact of other environmental stressors: A significant correlation has been observed between Sty1/Aft1dependent genes that are upregulated during early nitrogen starvation and those upregulated in response to other environmental stresses [69]. In addition, many meiotic experiments are carried out in temperature sensitive mutants which may be influencing the observed expression patterns. For these reasons we propose that other mitotic stressors, such as temperature stress, may influence transcription of $m e u 27^{+}$and in turn contribute to regulation of checkpoint.

Effect of convergent transcription on other DNA damage checkpoint genes: Several DNA damage checkpoint genes have convergent gene pairs, many of which have the potential to be induced under environmental stress. It is worth while to explore the transcriptional interference effect(s) of other convergent checkpoint genes to see if this regulatory mechanism is more wide-spread for modulating checkpoint induction and maintenance. 


\section{Appendix A:}

\section{DNA Damage Checkpoint Convergent Pairs}

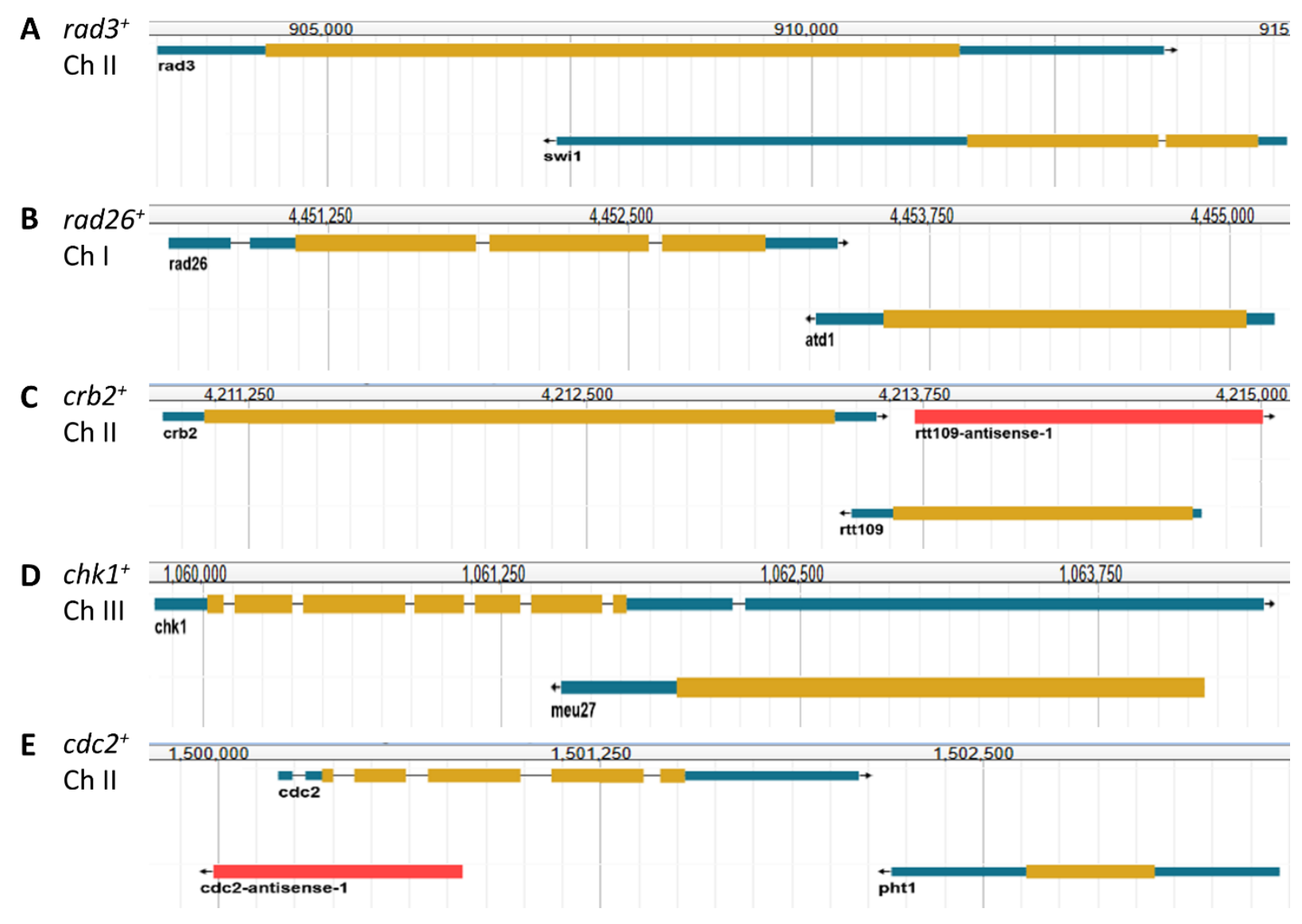

Figure A1. Chromosome mapping of convergent DNA damage checkpoint genes

DNA damage checkpoint genes and their convergent gene pairs mapped to chromosomal locations. Chromosome numbers are to the left of the images; DNA sequence numbers (in nucleotides) are above the strands. Both coding sequences (yellow) and UTRs (blue) are shown. Images adapted from the online fission yeast database, PomBase (A) Apical kinase: $\mathrm{rad}^{+}$and $\mathrm{swi1}^{+}$; (B) Rad3 associate protein: $\mathrm{rad}_{26^{+}}$and

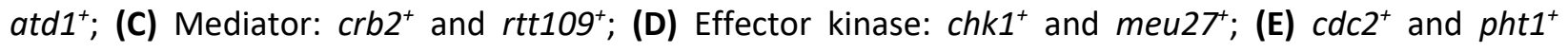
Thank you to Valarie Wood and the PomBase team for the use of this image from www.pombase.org. 


\section{Appendix B:}

\section{Strain Construction}

This section outlines the amino acid sequences of the strains designed for this research and data from experiments confirming successful strain construction. In addition, a comparison between the parent strains, wild-type and Chk1-HA is included.

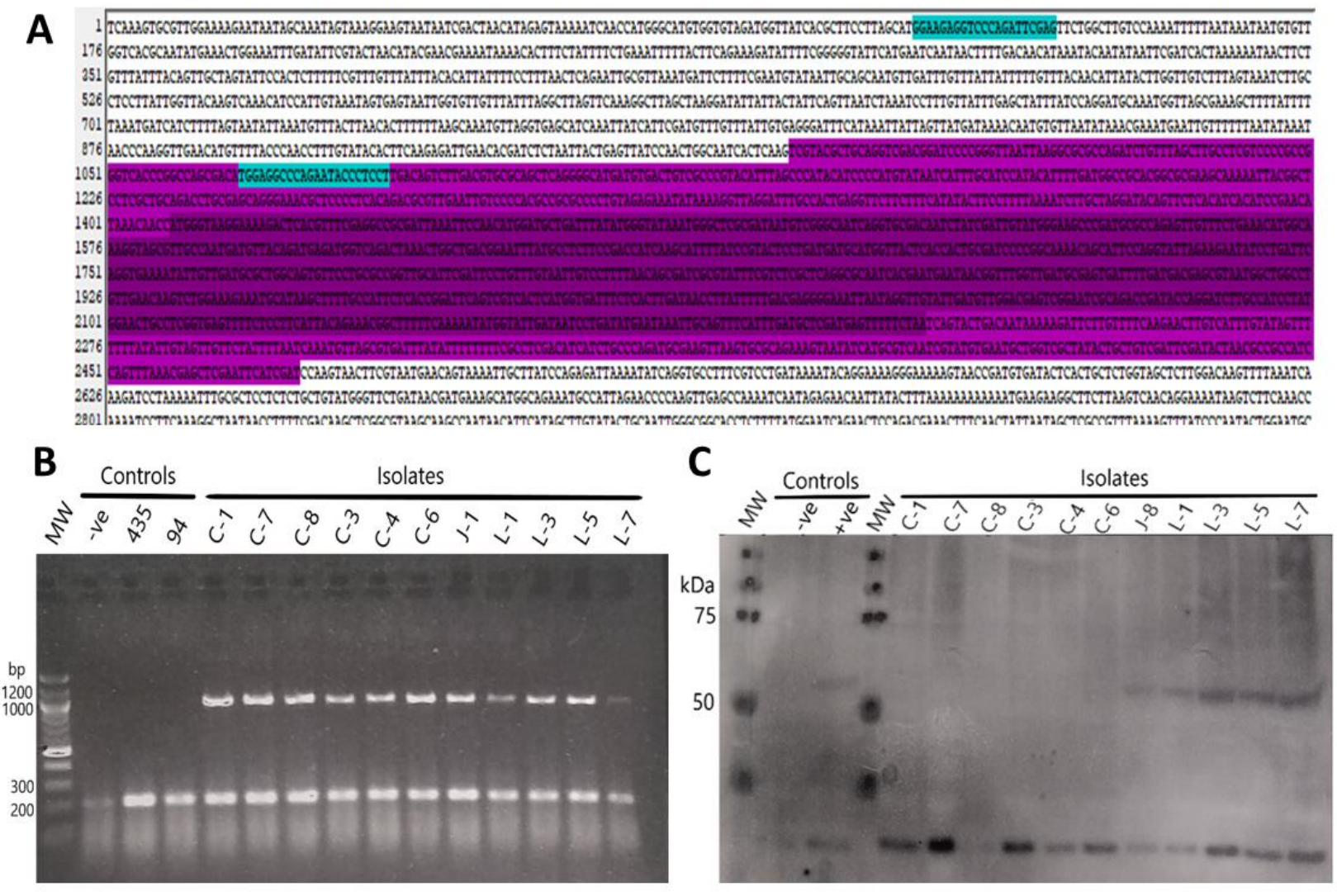

\section{Figure B1. Confirmation of Pmeu27D strain construction}

(A) The A Plasmid Editor (ApE) file depicting the incorporated KanMX6 integration fragment (purple; KanMX6 dark purple), upstream of the meu27 start codon (removed); also shown are the primer locations (cyan) used to confirm by PCR; expected size: 1246bp; (B) Agarose gel (1.5\%) of isolates; successful KanMX6 integration; size: 1200 bp; actin: 200bp; (C) Western blot: Chk1-HA candidate isolates post strain construction; expected size: $\sim 56 \mathrm{kDa}$ 

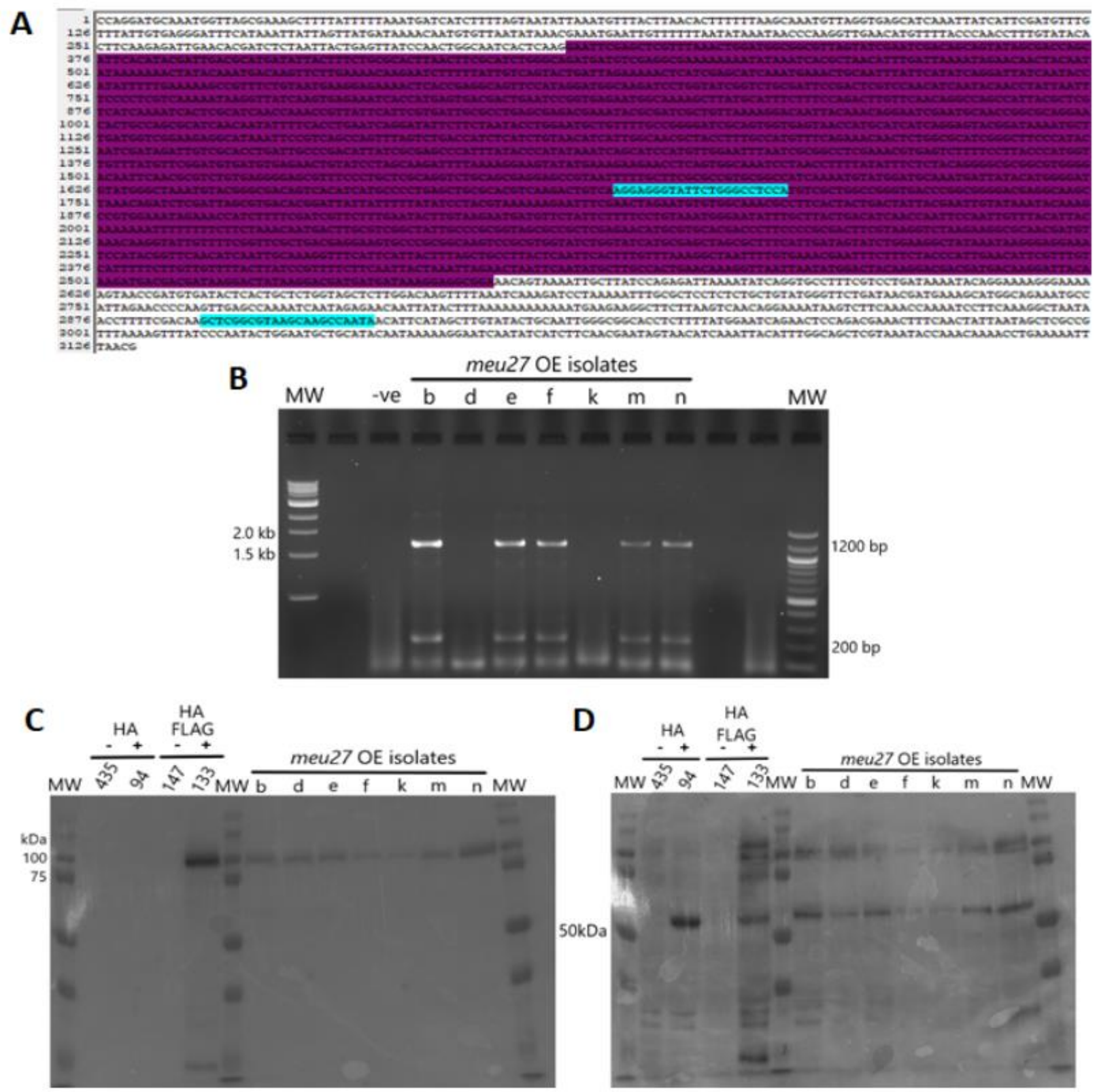

\section{Figure B2. Confirmation of meu27+OE strain construction}

(A) ApE file of incorporated KanMX6::pURG1::FLAG integration fragment (purple) upstream of the meu27 start codon (removed); primer locations (cyan) to confirm integration by PCR; expected size: 1220bp; actin: 200bp; (B) Agarose gel (1.5\%) of isolates; successful KanMX6::pURG1::FLAG integration; size: 1200bp; actin: 200bp; (C) Western blot: FLAG-Meu27 (size: 86kDa) of candidate isolates during strain construction; (D) Western blot: Chk1-HA (size: $\sim 56 \mathrm{kDa}$ ) of candidate isolates during strain construction 

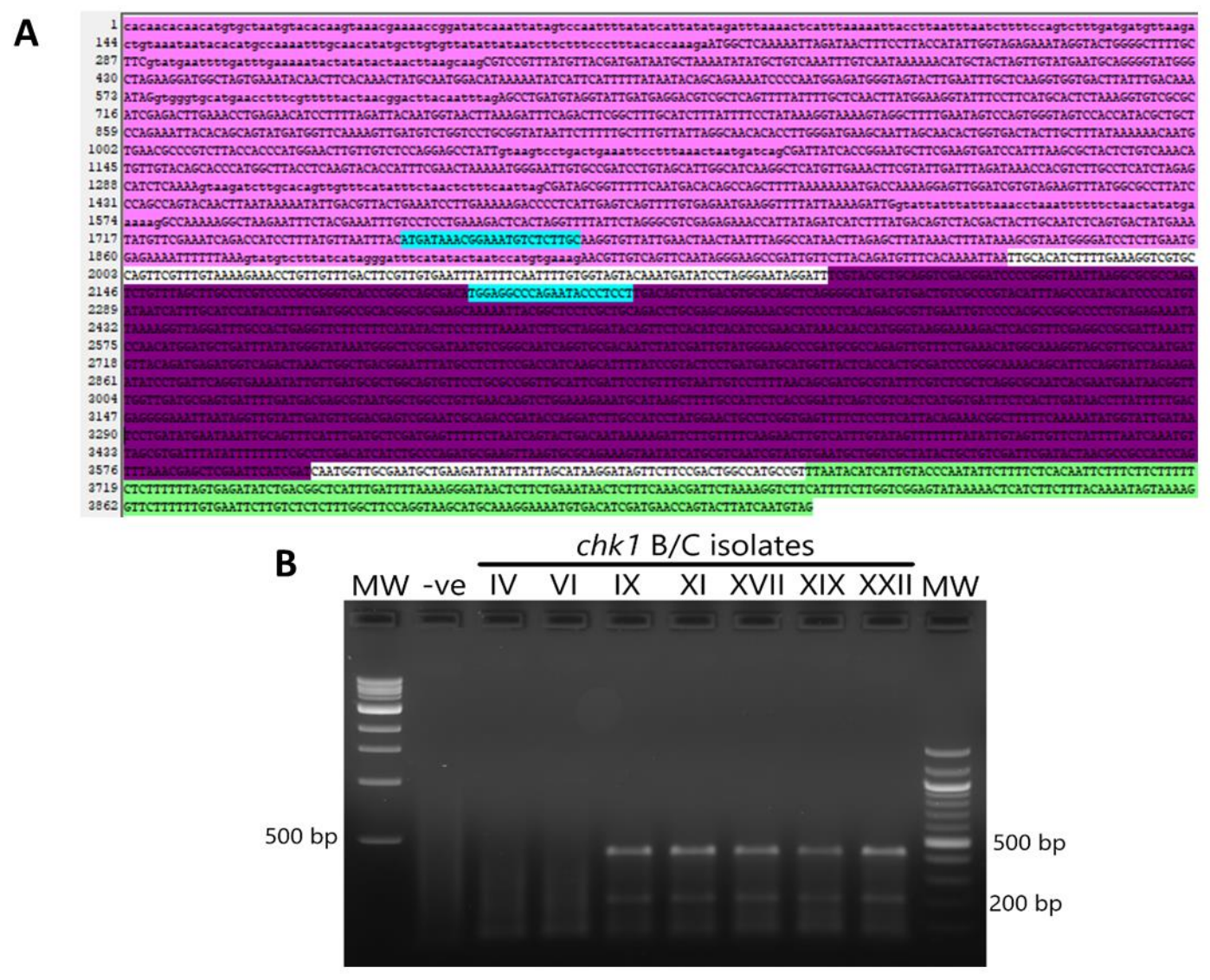

Figure B3. Confirmation of $c h k 1^{+}>>K a n M X 6>><<m e u 27^{+}$strain construction

(A) ApE file of incorporated KanMX6 integration fragment (purple) in between chk1+ (pink) and meu27+ (green); depicts primer locations (cyan) for confirmation by PCR; expected size: 460bp (B) Agarose gel (1.5\%) of isolates; successful KanMX6 integration; size: 500bp; actin: 200bp

A

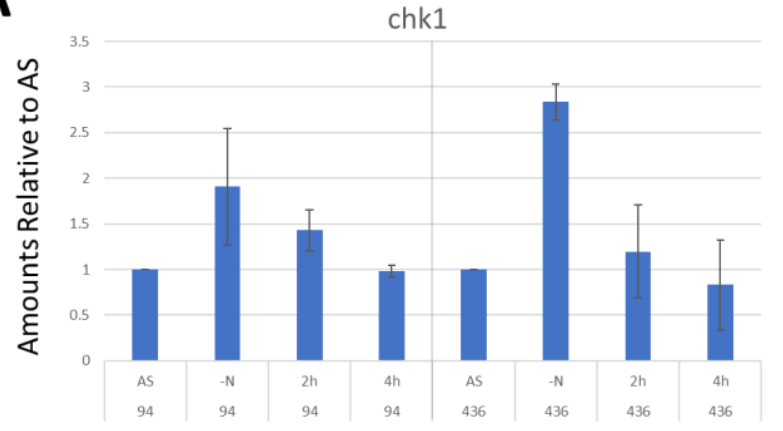

B

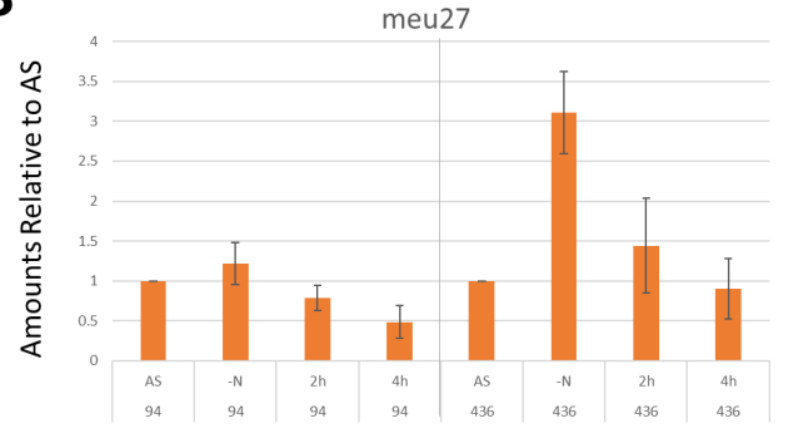

Figure B4. Comparison of wild-type and Chk1-HA RNA levels

RNA levels of chk1 and meu27 in wild-type (WT) and Chk1-HA strains using the $2^{-\Delta \Delta C T}$ method, relative to the asynchronous (AS) levels, "AS-normalized" (A) chk1 levels; (B) meu27 levels 


\section{List of Abbreviations}

S. cerevisiae Saccharomyces cerevisiae

S. pombe Schizosaccharomyces pombe

9-1-1 Rad9-Hus1-Rad1 complex

AMPK AMP-activated protein kinase

ApE A Plasmid Editor software

AS Asynchronous

ATM Ataxia telangiectasia mutated serine/threonine kinase

ATR Ataxia telangiectasia and $\operatorname{Rad} 3$ related protein

CDK Cyclin-dependent kinase

Chk1 Checkpoint kinase 1

CVT Convergent transcription

DAPI 4', 6-diamidino-2phenylindole

DABCO 1, 4-diazabicyclo[2,2,2]octane

DNA Deoxyribonucleic acid

dNTP Deoxyribonucleoside 5'-triphosphates

DSB Double-stranded breaks

DSBR Double-stranded break repair

dsRNA Double-stranded RNA

EDTA Ethylenediaminetetraacetic acid

ELN Extremely low nitrogen; EMM with trace amounts of nitrogen $\left(\mathrm{NH}_{4} \mathrm{Cl}\right)$ 


\section{ABBREVIATIONS}

EMM Edinburgh minimal medium

EMM-N EMM without nitrogen

G0 G zero phase; cellular quiescence

G1 Gap 1 phase

G2 Gap 2 phase

HA Hemagglutinin epitope tag

HRP Horseradish peroxidase

$\mathrm{I}_{2} \quad$ Iodine

lncRNA Long non-coding RNA

M phase Mitosis phase

meiS phase Meiotic S phase

MRN Mre11-Rad50-Nbs1 complex

mRNA Messenger RNA

miRNA Micro RNA

MSG Monosodium glutamate

ncRNA non-coding RNA

$\mathrm{NH}_{4} \mathrm{Cl} \quad$ Ammonium chloride

PBS-T Phosphate buffered saline with Tween-20

PCR Polymerase Chain Reaction

PKA Protein kinase A pathway

Pmeu274 meu $27^{+}$promoter knockout strain 


\begin{tabular}{|c|c|}
\hline \\
\hline \multicolumn{2}{|r|}{ Pombe minimal glutamate } \\
\hline PVDF & Polyvinylidene difluoride \\
\hline RISC & RNA-induced silencing complex \\
\hline RNAi & RNA interference \\
\hline RNAPs & DNA-dependent RNA polymerases \\
\hline RPA & Replication Protein A complex \\
\hline RT & Room temperature \\
\hline RT-qPCR & Quantitative reverse transcription PCR \\
\hline RSA & Random spore analysis \\
\hline S phase & DNA synthesis phase \\
\hline SDS & Sodium dodecyl sulfate \\
\hline SDS-PAGE & Sodium dodecyl sulfate polyacrylamide gel electrophoresis \\
\hline shRNA & Short hairpin RNA \\
\hline siRNA & Small interfering RNA \\
\hline sncRNA & Small non-coding RNA \\
\hline ssDNA & Single-stranded DNA \\
\hline TCA & Trichloroacetic acid \\
\hline TFs & Transcription factors \\
\hline TOR & Target of rapamycin signalling pathway \\
\hline TSS & Transcriptional start site \\
\hline YES & Yeast extract with supplements \\
\hline
\end{tabular}




\section{References}

[1] C. S. Hoffman, V. Wood, and P. A. Fantes, "An Ancient Yeast for Young Geneticists: A Primer on the Schizosaccharomyces pombe Model System," Genetics, vol. 201, no. 2, pp. 403-423, Oct. 2015.

[2] S. L. Forsburg, "Fission Yeast Cell Cycle," PombeNet, 2015. [Online]. Available: https://www-bcf.usc.edu/ forsburg/main4.html.

[3] N. Rhind and P. Russell, "Mitotic DNA damage and replication checkpoints in yeast," Current Opinion in Cell Biology, vol. 10, no. 6, pp. 749-758, Dec. 1998.

[4] F. J. van Werven and A. Amon, "Regulation of entry into gametogenesis," Philosophical Transactions of the Royal Society B: Biological Sciences, vol. 366, no. 1584, pp. 3521-3531, Dec. 2011.

[5] S. S. Y. Su, Y. Tanaka, I. Samejima, K. Tanaka, and M. Yanagida, "A nitrogen starvationinduced dormant G0 state in fission yeast: the establishment from uncommitted G1 state and its delay for return to proliferation," Journal of Cell Science, vol. 109, pp. 1347-1357, 1996.

[6] N. Valbuena and S. Moreno, "TOR and PKA Pathways Synergize at the Level of the Ste11 Transcription Factor to Prevent Mating and Meiosis in Fission Yeast," PLoS ONE, vol. 5, no. 7, p. e11514, Jul. 2010.

[7] N. Cremona, K. Potter, and J. A. Wise, "A meiotic gene regulatory cascade driven by alternative fates for newly synthesized transcripts," Molecular Biology of the Cell, vol. 22, no. 1, pp. 66-77, Jan. 2011.

[8] Z. Kuang, J. D. Boeke, and S. Canzar, "The dynamic landscape of fission yeast meiosis alternative-splice isoforms," Genome Research, vol. 27, no. 1, pp. 145-156, Jan. 2017.

[9] D. A. Bitton et al., "Widespread exon skipping triggers degradation by nuclear RNA surveillance in fission yeast," Genome Research, vol. 25, no. 6, pp. 884-896, Jun. 2015.

[10] D. P. Bartel, "MicroRNAs: Genomics, Biogenesis, Mechanism, and Function," Cell, vol. 116, pp. 281-297, Jan. 2004.

[11] J. R. Alvarez-Dominguez, W. Hu, and H. F. Lodish, "Regulation of Eukaryotic Cell Differentiation by Long Non-coding RNAs," in Molecular Biology of Long Non-coding RNAs, A. M. Khalil and J. Coller, Eds. New York, NY: Springer New York, 2013, pp. 1567.

[12] R. B.-T. Perry and I. Ulitsky, "The functions of long noncoding RNAs in development and stem cells," Development, vol. 143, no. 21, pp. 3882-3894, Nov. 2016.

[13] D. G. Pankratz and S. L. Forsburg, "Meiotic S-Phase Damage Activates Recombination without Checkpoint Arrest口D," Molecular Biology of the Cell, vol. 16, p. 10, 2005.

[14] K. Shearwin, B. Callen, and J. Egan, "Transcriptional interference - a crash course," Trends in Genetics, vol. 21, no. 6, pp. 339-345, Jun. 2005.

[15] A. C. Palmer, J. B. Egan, and K. E. Shearwin, "Transcriptional interference by RNA polymerase pausing and dislodgement of transcription factors," Transcription, vol. 2, no. 1, pp. 9-14, Jan. 2011.

[16] R. Origa and P. Moi, "Alpha-Thalassemia," p. 25.

[17] N. R. Pannunzio and M. R. Lieber, "Dissecting the Roles of Divergent and Convergent Transcription in Chromosome Instability," Cell Reports, vol. 14, no. 5, pp. 1025-1031, Feb. 2016. 


\section{REFERENCES}

[18] A. Mazo, J. W. Hodgson, S. Petruk, Y. Sedkov, and H. W. Brock, "Transcriptional interference: an unexpected layer of complexity in gene regulation," Journal of Cell Science, vol. 120, no. 16, pp. 2755-2761, Aug. 2007.

[19] N. Tran, M. J. Cairns, I. W. Dawes, and G. M. Arndt, "Expressing functional siRNAs in mammalian cells using convergent transcription," BMC Biotechnology, p. 9, 2003.

[20] D. J. Hobson, W. Wei, L. M. Steinmetz, and J. Q. Svejstrup, "RNA Polymerase II Collision Interrupts Convergent Transcription," Molecular Cell, vol. 48, no. 3, pp. 365-374, Nov. 2012.

[21] M. Gullerova and N. J. Proudfoot, "Convergent transcription induces transcriptional gene silencing in fission yeast and mammalian cells," Nature Structural \& Molecular Biology, vol. 19, no. 11, pp. 1193-1201, Nov. 2012.

[22] E. Giordano, R. Rendina, I. Peluso, and M. Furia, "RNAi Triggered by Symmetrically Transcribed Transgenes in," p. 12.

[23] A. Djikeng, H. Shi, C. Tschudi, and E. Ullu, "RNA interference in Trypanosoma brucei: cloning of small interfering RNAs provides evidence for retroposon-derived 24-26nucleotide RNAs," p. 10.

[24] R. Heery, S. Finn, S. Cuffe, and S. Gray, "Long Non-Coding RNAs: Key Regulators of Epithelial-Mesenchymal Transition, Tumour Drug Resistance and Cancer Stem Cells," Cancers, vol. 9, no. 12, p. 38, Apr. 2017.

[25] K. N. Smith, J. Starmer, S. C. Miller, P. Sethupathy, and T. Magnuson, "Long Noncoding RNA Moderates MicroRNA Activity to Maintain Self-Renewal in Embryonic Stem Cells," Stem Cell Reports, vol. 9, no. 1, pp. 108-121, Jul. 2017.

[26] T. Ni et al., "The Prevalence and Regulation of Antisense Transcripts in Schizosaccharomyces pombe," PLoS ONE, vol. 5, no. 12, p. e15271, Dec. 2010.

[27] J. A. Wilson et al., "RNA interference blocks gene expression and RNA synthesis from hepatitis C replicons propagated in human liver cells," Proceedings of the National Academy of Sciences, vol. 100, no. 5, pp. 2783-2788, Mar. 2003.

[28] M. Gullerova, D. Moazed, and N. J. Proudfoot, "Autoregulation of convergent RNAi genes in fission yeast," Genes \& Development, vol. 25, no. 6, pp. 556-568, Mar. 2011.

[29] S. Chen et al., "LncRNAs and their role in cancer stem cells," Oncotarget, vol. 8, no. 66, Dec. 2017.

[30] L. Salmena, L. Poliseno, Y. Tay, L. Kats, and P. P. Pandolfi, "A ceRNA hypothesis: the Rosetta stone of a hidden RNA language?," Cell, vol. 146, no. 3, pp. 353-358, Aug. 2011.

[31] F. A. Karreth et al., "In vivo identification of tumor suppressive PTEN ceRNAs in an oncogenic BRAF-induced mouse model of melanoma," Cell, vol. 147, no. 2, pp. 382-395, Oct. 2011.

[32] S. Wang, S. Huang, and Y. L. Sun, "Epithelial-Mesenchymal Transition in Pancreatic Cancer: A Review," BioMed Research International, vol. 2017, pp. 1-10, 2017.

[33] P. J. Batista and H. Y. Chang, "Long Noncoding RNAs: Cellular Address Codes in Development and Disease," Cell, vol. 152, no. 6, pp. 1298-1307, Mar. 2013.

[34] S. Lim and P. Kaldis, "Cdks, cyclins and CKIs: roles beyond cell cycle regulation," Development, vol. 140, no. 15, pp. 3079-3093, Aug. 2013.

[35] R. S. DiPaola, “To Arrest or Not To G2-M Cell-Cycle Arrest," p. 5.

[36] H. Zhao and H. Piwnica-Worms, "ATR-Mediated Checkpoint Pathways Regulate Phosphorylation and Activation of Human Chk1," Molecular and Cellular Biology, vol. 21, no. 13, pp. 4129-4139, Jul. 2001. 


\section{REFERENCES}

[37] S. A. Sabatinos, T. L. Mastro, M. D. Green, and S. L. Forsburg, "A Mammalian-Like DNA Damage Response of Fission Yeast to Nucleoside Analogs," Genetics, vol. 193, no. 1, pp. 143-157, Jan. 2013.

[38] T. D. Wolkow and T. Enoch, "Fission Yeast Rad26 Is a Regulatory Subunit of the Rad3 Checkpoint Kinase," Molecular Biology of the Cell, vol. 13, no. 2, pp. 480-492, Feb. 2002.

[39] A. Maréchal and L. Zou, "RPA-coated single-stranded DNA as a platform for posttranslational modifications in the DNA damage response," Cell Research, vol. 25, no. 1, pp. 9-23, Jan. 2015.

[40] N. Rhind, B. Furnari, and P. Russell, "Cdc2 tyrosine phosphorylation is required for the DNA damage checkpoint in fission yeast.," Genes \& Development, vol. 11, no. 4, pp. 504511, Feb. 1997.

[41] M. Yue, L. Zeng, A. Singh, and Y. Xu, "Rad4 Mainly Functions in Chk1-Mediated DNA Damage Checkpoint Pathway as a Scaffold Protein in the Fission Yeast Schizosaccharomyces pombe," PLoS ONE, vol. 9, no. 3, p. e92936, Mar. 2014.

[42] T. M. Nakamura, L.-L. Du, C. Redon, and P. Russell, "Histone H2A Phosphorylation Controls Crb2 Recruitment at DNA Breaks, Maintains Checkpoint Arrest, and Influences DNA Repair in Fission Yeast," Molecular and Cellular Biology, vol. 24, no. 14, pp. 62156230, Jul. 2004.

[43] C. Redon, D. R. Pilch, and W. M. Bonner, "Genetic Analysis of Saccharomyces cerevisiae H2A Serine 129 Mutant Suggests a Functional Relationship Between H2A and the Sister-Chromatid Cohesion Partners Csm3-Tof1 for the Repair of Topoisomerase I-Induced DNA Damage," Genetics, vol. 172, no. 1, pp. 67-76, Jan. 2006.

[44] S. L. Sanders, M. Portoso, J. Mata, J. Bähler, R. C. Allshire, and T. Kouzarides, "Methylation of Histone H4 Lysine 20 Controls Recruitment of Crb2 to Sites of DNA Damage," Cell, vol. 119, no. 5, pp. 603-614, Nov. 2004.

[45] T. Carneiro et al., "Telomeres avoid end detection by severing the checkpoint signal transduction pathway," Nature, vol. 467, no. 7312, pp. 228-232, Sep. 2010.

[46] J. Audry, J. Wang, J. Eisenstatt, K. Berkner, and K. Runge, "The inhibition of checkpoint activation by telomeres does not involve exclusion of dimethylation of histone H4 lysine 20 (H4K20me2)," F1000Research, vol. 7, no. 1027, pp. 1-16, Nov. 2018.

[47] H. MURAKAMI and P. NURSE, "DNA replication and damage checkpoints and meiotic cell cycle controls in the fission and budding yeasts," p. 12, 2000.

[48] N. Kishimoto and I. Yamashita, "Multiple pathways regulating fission yeast mitosis upon environmental stresses," Yeast, vol. 16, no. 7, pp. 597-609, May 2000.

[49] A. M. Carr, M. Moudjout, and N. J. Bentley, "The chkl pathway is required to prevent mitosis following cell-cycle arrest at "start," p. 12.

[50] S. Francesconi, M. Smeets, M. Grenon, J. Tillit, J. Blaisonneau, and G. Baldacci, "Fission yeast chk1 mutants show distinct responses to different types of DNA damaging treatments," Genes to Cells, vol. 7, no. 7, pp. 663-673, Jul. 2002.

[51] N. Walworth and R. Bernards, "Rad-dependent response of the chkl-encoded protein kinase at the DNA damage checkpoint," Trends in Genetics, vol. 12, no. 6, p. 211, Jun. 1996.

[52] S. Sabatinos, "NSERC Discovery Grant Project Proposal." 2014.

[53] E. Noguchi, C. Noguchi, W. H. McDonald, J. R. Yates, and P. Russell, "Swi1 and Swi3 Are Components of a Replication Fork Protection Complex in Fission Yeast," Molecular and Cellular Biology, vol. 24, no. 19, pp. 8342-8355, Oct. 2004. 


\section{REFERENCES}

[54] C. Noguchi et al., "Genetic controls of DNA damage avoidance in response to acetaldehyde in fission yeast," Cell Cycle, vol. 16, no. 1, pp. 45-58, Jan. 2017.

[55] J. F. Bazan, "An old HAT in human p300/CBP and yeast Rtt109," Cell Cycle, vol. 7, no. 12, pp. 1884-1886, Jun. 2008.

[56] H.-S. Kim et al., "An acetylated form of histone H2A.Z regulates chromosome architecture in Schizosaccharomyces pombe," Nature Structural \& Molecular Biology, vol. 16, no. 12, pp. 1286-1293, Dec. 2009.

[57] T. Watanabe, "Comprehensive isolation of meiosis-specific genes identifies novel proteins and unusual non-coding transcripts in Schizosaccharomyces pombe," Nucleic Acids Research, vol. 29, no. 11, pp. 2327-2337, Jun. 2001.

[58] J. Hayles et al., "A genome-wide resource of cell cycle and cell shape genes of fission yeast," Open Biology, vol. 3, no. 5, p. 130053, May 2013.

[59] J. Lee et al., "Chromatin remodeller Fun30Fft3 induces nucleosome disassembly to facilitate RNA polymerase II elongation," Nature Communications, vol. 8, no. 1, Apr. 2017.

[60] C. Rallis, S. Townsend, and J. Bähler, "Genetic interactions and functional analyses of the fission yeast gsk3 and amk2 single and double mutants defective in TORC1-dependent processes," Scientific Reports, vol. 7, no. 1, May 2017.

[61] M. Zofall, S. Yamanaka, F. E. Reyes-Turcu, K. Zhang, C. Rubin, and S. I. S. Grewal, "RNA Elimination Machinery Targeting Meiotic mRNAs Promotes Facultative Heterochromatin Formation," Science, vol. 335, no. 6064, pp. 96-100, Jan. 2012.

[62] M. D. Krawchuk and W. P. Wahls, "High-efficiency gene targeting in Schizosaccharomyces pombe using a modular, PCR-based approach with long tracts of flanking homology," Yeast (Chichester, England), vol. 15, no. 13, p. 1419, 1999.

[63] C. Noguchi, M. V. Garabedian, M. Malik, and E. Noguchi, "A vector system for genomic FLAG epitope-tagging in Schizosaccharomyces pombe," Biotechnology Journal, vol. 3, no. 9-10, pp. 1280-1285, Oct. 2008.

[64] S. A. Sabatinos and S. L. Forsburg, "Molecular Genetics of Schizosaccharomyces pombe," in Methods in Enzymology, vol. 470, Elsevier, 2010, pp. 759-795.

[65] X. Rao, X. Huang, Z. Zhou, and X. Lin, "An improvement of the $2^{\wedge}$ (-delta delta CT) method for quantitative real-time polymerase chain reaction data analysis," p. 13, 2014.

[66] J. Bähler et al., "Heterologous modules for efficient and versatile PCR-based gene targeting in Schizosaccharomyces pombe," Yeast, vol. 14, pp. 943-951, 1998.

[67] N. Walworth, S. Davey, and D. Beach, "Fission yeast chk1 protein kinase links the rad checkpoint pathway to cdc2," Nature, vol. 363, pp. 368-371, May 1993.

[68] S. Mochida and M. Yanagida, "Distinct modes of DNA damage response in S. pombe G0 and vegetative cells: Damage repair in G0 cells," Genes to Cells, vol. 11, no. 1, pp. 13-27, Nov. 2005.

[69] C. Kristell, J. Orzechowski Westholm, I. Olsson, H. Ronne, J. Komorowski, and P. Bjerling, "Nitrogen depletion in the fission yeast Schizosaccharomyces pombe causes nucleosome loss in both promoters and coding regions of activated genes," Genome Research, vol. 20, no. 3, pp. 361-371, Mar. 2010.

[70] S. Keeney, C. N. Giroux, and N. Kleckner, "Meiosis-Specific DNA Double-Strand Breaks Are Catalyzed by Spo11, a Member of a Widely Conserved Protein Family," Cell, vol. 88, no. 3, pp. 375-384, Feb. 1997. 


\section{REFERENCES}

[71] W. D. Sharif, G. G. Glick, M. K. Davidson, and W. P. Wahls, "Distinct functions of S. pombe Rec12 (Spo11) protein and Rec12- dependent crossover recombination (chiasmata) in meiosis I; and a requirement for Rec12 in meiosis II," p. 14, 2002.

[72] F. Baudat, K. Manova, J. P. Yuen, M. Jasin, and S. Keeney, "Chromosome Synapsis Defects and Sexually Dimorphic Meiotic Progression in Mice Lacking Spo11," Molecular Cell, vol. 6, no. 5, pp. 989-998, Nov. 2000.

[73] M. Karimian and A. Taherian, "SPO11-C631T Gene Polymorphism: Association With Male Infertility and an in Silico-Analysis," p. 9.

[74] J. Mata, R. Lyne, G. Burns, and J. Bähler, "The transcriptional program of meiosis and sporulation in fission yeast," Nature Genetics, vol. 32, no. 1, pp. 143-147, Sep. 2002.

[75] N. Pabla, K. Bhatt, and Z. Dong, "Checkpoint kinase 1 (Chk1)-short is a splice variant and endogenous inhibitor of Chk1 that regulates cell cycle and DNA damage checkpoints," Proceedings of the National Academy of Sciences, vol. 109, no. 1, pp. 197-202, Jan. 2012.

[76] D. Chen et al., "Global Transcriptional Responses of Fission Yeast to Environmental Stress," Molecular Biology of the Cell, vol. 14, no. 1, pp. 214-229, Jan. 2003.

[77] C. Salat-Canela et al., "Deciphering the role of the signal- and Sty1 kinase-dependent phosphorylation of the stress-responsive transcription factor Atfl on gene activation," Journal of Biological Chemistry, vol. 292, no. 33, pp. 13635-13644, Aug. 2017.

[78] T. Nakamura, M. Nakamura-Kubo, A. Hirata, and C. Shimoda, "The Schizosaccharomyces pombe spo3 ${ }^{+}$Gene Is Required for Assembly of the Forespore Membrane and Genetically Interacts with psyl ${ }^{+}$-encoding Syntaxin-like Protein," Molecular Biology of the Cell, vol. 12, no. 12, pp. 3955-3972, Dec. 2001.

[79] Y. Maeda, J. Kashiwazaki, C. Shimoda, and T. Nakamura, "The Schizosaccharomyces pombe Syntaxin 1 Homolog, Psy1, Is Essential in the Development of the Forespore Membrane," Bioscience, Biotechnology, and Biochemistry, vol. 73, no. 2, pp. 339-345, Feb. 2009. 